\title{
Morphological Plasticity of Motor Axons in Drosophila Mutants with Altered Excitability
}

\author{
Vivian Budnik, Yi Zhong, and Chun-Fang Wu \\ Department of Biology, University of lowa, lowa City, lowa 52242
}

An anatomical and electrophysiological study of Drosophila mutants has been made to determine the effect of altered electrical activity on the development and maintenance of larval neuromuscular junctions. We examined motor axon terminals of (1) hyperexcitable mutants Shaker (Sh), ether a go-go (eag), Hyperkinetic (Hk), and Duplication of para (Dp para ${ }^{+}$; and (2) mutants with reduced excitability, no action potential (napts) and paralytic (parats 1 ).

Nerve terminals innervating larval body-wall muscles were visualized by using anti-HRP immunocytochemistry, which specifically stains neurons in insect species. In wild-type larvae, motor axon terminals were distributed in a sterotypic fashion. However, in combinations of eag and $S h$ alleles, the basic pattern of innervation was altered. There was an increase in both the number of higher-order axonal branches over the muscles and the number of varicosities on the neurites. A similar phenomenon was found in the double mutant $H k$ eag and, to a lesser extent, in $D p$ para ${ }^{+}$and $D p$ para ${ }^{+} S h$ mutants. It is known that at permissive temperature the napts, but not parats ${ }^{t}$, mutation decreases excitability of larval motor axons and suppresses the behavioral phenotypes of $\mathbf{S h}$, eag, and $H k$. In the mutant nap ${ }^{t s}$ (reared at permissive temperature), a slight decrease in the extent of branching was observed. Yet, when combined with eag Sh, napts completely reversed the morphological abnormality in eag $S h$ mutants. No such reversion was observed in parats 1 eag $S h$ mutants.

The endogenous patterns of electrical activity at the neuromuscular junction were analyzed by extracellular recordings in a semi-intact larval preparation. Recordings from wild-type body-wall muscles revealed rhythmic bursts of spikes. In eag Sh mutants, this rhythmic activity was accompanied by or superimposed on periods of strong tonic activity. This abnormal pattern of activity could be partially suppressed by nap's in combination with eag $\mathbf{S h}$.

The invertebrate CNS has long been viewed as having a rigid stereotypic organization that precludes much plasticity (see Murphey, 1986). In recent years, however, studies of long-term physiological and anatomical changes in Aplysia during behav-

Received Apr. 9, 1990; revised July 30, 1990; accepted Aug. 1, 1990.

We are grateful to Susan Mikkelsen for her aid in the study of intersegmental differences of motor innervation. We also thank Drs. B. Ganetzky and M. Stern for providing us with the $D p$ para $^{+}$fly stocks and Drs. Michel Gho, Michael Gorczyca, and Mitsuyoshi Saito for helpful comments on the manuscript.

Correspondence should be addressed to Vivian Budnik, Department of Zoology, Morrill Science Center, University of Massachusetts, Amherst, MA 01003.

Copyright (C) 1990 Society for Neuroscience $0270-6474 / 90 / 113754-15 \$ 03.00 / 0$ ioral conditioning (Kandel et al., 1986; Bailey and Chen, $1988 \mathrm{a}, \mathrm{b}$ ), as well as studies of regeneration (Murphey and Lemere, 1984; Shepherd and Murphey, 1986; Loer et al., 1987; Loer and Kristan, 1989), have changed this view. Instead, it has become apparent that, even though the behavioral repertoire of invertebrates is less complex than that of vertebrates, developmental and physiological plasticity is a common feature (reviewed in Lnenicka and Murphey, 1989; see also Technau, 1984; Meinertzhagen, 1989).

The mechanisms underlying neuronal plasticity remain unknown in most cases. However, a factor that has been widely implicated in plastic processes is electrical activity (Hubel et al., 1977; Harris, 1981; Meyer, 1982; Sanes and Constantine-Paton, 1983; Lnenicka and Murphey, 1989; Schmidt and Tieman, 1989). In the optic tectum of vertebrates, for example, it has been shown that correlated activity in retinal ganglion cells determines the fine distribution of retinal terminals in the tectum. Any perturbation of this pattern of activity leads to defects in the final pattern of connections and therefore in the size and or shape of the receptive field of these neurons in the tectum (Harris, 1980; Meyer, 1982; Schmidt and Edwards, 1983). In the vertebrate neuromuscular junction, it has also been shown that disruptions in the level of activity of motor axons lead to changes in morphology of axon terminals (Duchen and Strich, 1968; Brown and Ironton, 1977; Holland and Brown, 1980).

Very little is known about how activity levels affect the development of neuronal connectivity in invertebrates (reviewed in Lnenicka and Murphey, 1989). Lnenicka et al. (1986) showed that chronic stimulation of relatively silent phasic motoneurons in the crayfish changed the ultrastructurc of its synaptic terminals. This change was reflected in an increased number of varicosities in the nerve projecting to the muscle, larger terminals, and greater synaptic contact area. This altered phenotype resembled the properties of tonic motor axon terminals in arthropods (Atwood and Johnston, 1968; Atwood and Jahromi, 1978; Hill and Govind, 1981; Titmus, 1981). On the other hand, Cohan and Kater (1986) have shown that electrical activity suppresses neurite elongation and growth cone motility in some cultured Helisoma neurons.

A genetic approach to the study of neuronal plasticity can be made in Drosophila by using a number of neural mutations that either eliminate nerve activity or increase excitability (Burg and $\mathrm{Wu}, 1986,1989$ ). We have initiated an anatomical and physiological study of neuromuscular junctions in the hyperexcitable mutants-Shaker (Sh), ether a go-go (eag), and Hyperkinetic $(H k)-$ and in mutants with reduced excitability-no action potential (nap ${ }^{s}$ ) and paralytic (para ${ }^{t s l}$ ). 
$S h$, eag, and $H k$ were isolated by their phenotype of anesthesia-induced leg shaking (Kaplan and Trout, 1969). The $S h$ gene has been well characterized at the molecular level and found to code for the $I_{A}$ potassium-channel protein (Bauman et al., 1987; Kamb et al., 1987; Papazian et al., 1987; Tempel et al., 1987). Sh mutant allcles incrcasc transmittcr relcase at the larval neuromuscular junction (Jan et al., 1977; Ganetzky and $\mathrm{Wu}, 1982 \mathrm{a}$ ) and decrease or eliminate the transient $\mathrm{K}^{+}$-current $I_{A}$ from pupal and larval muscles (Salkoff and Wyman, 1981; Wu and Haugland, 1985). Mutants at the eag locus display spontaneous action potentials in larval motor axons (Ganetzky and $\mathrm{Wu}, 1983)$. Voltage-clamp analysis of larval muscle currents reveals that the delayed rectifier $I_{K}$ and, in some alleles, $I_{A}$, are affected (Wu et al., 1983; Y. Zhong and C.-F. Wu, unpublished observations). The double mutant eag $S h$ shows synergistic interactions: both the release of neurotransmitter at the larval neuromuscular junction and the degree of adult leg shaking are greatly enhanced (Ganetzky and Wu, 1983). Hk mutants show abnormal neuronal activity in adult ventral ganglia (Ikeda and Kaplan, 1970) and stimulus-induced repetitive activity at the larval neuromuscular junction (Stern and Ganetzky, 1989). However, as for eag, the molecular nature of this mutation is still unknown.

The mutants para (Suzuki et al., 1971; Siddiqi and Benzer, 1976) and nap (Wu et al., 1978) were isolated on the basis of their temperature-dependent paralytic phenotype. Recent molecular studies indicate that the para gene most probably corresponds to the structural sodium channel gene, and that nap appears to be a regulatory gene, controlling the expression of para (Kernan et al., 1989; Loughney et al., 1989). At permissive temperature, the mutant allele para $^{i s I}$ appears physiologically normal, whereas napts mutants, because of a reduction in $\mathrm{Na}^{+}$ channel number (Kauvar, 1982; Jackson et al., 1984), already show alterations in axonal conduction even at room temperature (Wu and Ganetzky, 1980). At room temperature, nap can suppress the shaking phenotype of eag $S h$, as well as some physiological defects of eag and $S h$ (reviewed in Ganetzky and Wu, 1985).

Many of the above physiological studies have been carried out in the body-wall muscles of Drosophila larvae. In these muscles, 4 classes of potassium currents and a calcium current have been well characterized (Wu and Haugland, 1985; Gho and Mallart, 1986; Singh and Wu, 1989). Some of these currents have also been described at the single-channel level (Zagotta et al., 1988; Komatsu et al., 1990; Gorczyca and Wu, 1991). Several mutations that disrupt muscle currents, or alter neuromuscular transmission, have been characterized in the larval preparation (for review, see Ganetzky and Wu, 1986). In addition, anatomical aspects of the development and distribution of axon terminals in these muscles have been described (Johansen et al., $1989 \mathrm{a}, \mathrm{b})$. In this study, we used the larval neuromuscular preparation to examine the possible effect of altered activity on the morphology of motor axon terminals. We show that increasing cxcitability by simultaneous mutations in the $e a g$ and $S h$ genes or in the eag and $H k$ genes, or by augmenting the number of $\mathrm{para}^{+}$genes, leads to an increase in the ramification of branches on the muscles. In addition, there is a greater number of putative synaptic sites. These effects seen in eag Sh double mutants can be reversed by the mutation nap ${ }^{t s}$. Although the mechanisms underlying the morphological changes are not known, these results provide an independent line of evidence for the involvement of nerve activity in shaping neuronal arborizations in invertebrates. In addition, they also provide background for possible reinterpretation of the physiological defects observed on the neuromuscular junctions of these mutants (Jan et al., 1977; Ganetzky and Wu, 1982a,b; Stern and Ganetzky, 1989).

Some of the results have appeared in abstract form (Budnik et al., 1989b).

\section{Materials and Methods}

Fly stocks. All fly stocks were reared at room temperature $\left(22-25^{\circ} \mathrm{C}\right)$ in standard Drosophila food. As a wild type, the strain Canton-Special (CS) was used. Chromosome markers are described in Lindsley and Grell (1968). The mulations used are listed below.

eagl: Recessive ethyl methane sulfonate (EMS)-induced mutation located at map position 1-48 (Kaplan and Trout, 1969). This mutation removes about $50 \%$ of $I_{K}$ (Wu et al., 1983; Y. Zhong and C.-F. Wu, unpublished observations).

eag ${ }^{A P M}$ : This eag allele preferentially affects $I_{A}$ rather than $I_{K}$ in larval muscles (Ganetzky and $\mathrm{Wu}, 1983$; Y. Zhong and $\mathrm{C}$.-F. Wu, unpublished observations).

$H k^{i}$ : Recessive EMS-induced mutation located at map position 1-30 (Kaplan and Trout, 1969). This mutant shows reduced $I_{4}$ (Wu and Ganetzky, 1988) and, at high-frequency stimulation, displays prolonged excitatory junctional potentials (EJPs) at the larval neuromuscular junction (Stern and Ganetzky, 1989).

$n a p^{s}$ : Isolated by EMS mutagenesis (Wu et al., 1978). Flies bearing this mutation become paralyzed at $37^{\circ} \mathrm{C}$ due to action potentials blockade. Maps to position 2-56.

para $^{a s}$ : First described by Suzuki et al. (1971). These mutants become paralyzed at $29^{\circ} \mathrm{C}$. At this temperature, nerve conduction is completely blocked. Physiologically normal at permissive temperature (Wu and Ganetzky, 1980).

$S h^{\kappa S 133}$ : Described by Jan et al. (1977). Shows prolonged EJPs at the larval neuromuscular junction and completely removes $I_{A}$ in muscle. (For further physiological characterization, see Salkoff and Wyman, 1981; Wu and Haugland, 1985; Haughland and $\mathrm{Wu}, 1990$.)

$S h^{r K O} 120:$ Reduces but does not eliminate $I_{A}$ in larval muscle. It also has abnormal neuromuscular transmission similar to $S h^{K S 133}$ (Ganetzky and Wu, 1983; Wu and Haugland, 1985; Timpe and Jan, 1987). Maps to position 1-57.4.

$D p(1: 4) r^{\prime} f$. Translocation of the $\mathrm{X}$-chromosome region $14 \mathrm{~A}$ to $16 \mathrm{~A} 2$ to the fourth chromosome. This duplication contains the entire $\mathrm{para}^{+}$ gene and also covers $l(1) l^{D 23}$ and $D f(1) r^{D / 7}$ (see below). In this paper, this duplication will be referred to as $D p$ para ${ }^{+}$.

$l(1) l^{D 23}$. This is a recessive lethal mutation that lies close to, but is distinct from, para (Ganetzky, 1984), and that is covered by $D p(1: 4)$ $r^{+} f$.

$D f(1) r^{D 17}$. This is a deletion from $14 \mathrm{~F} 6$ to $15 \mathrm{~A} 6$ of the $\mathrm{X}$ chromosome that also lies close to para. This deletion is also covered by $D p(1: 4) r^{+} f$ (Stern et al., 1990).

The strains containing $D p(1: 4) r^{+} f, l(1) l^{D 23}$, and $D f(1) r^{D 17}$ were provided to us by Drs. M. Stern and B. Ganetzky.

Immunocytochemistry. Late third-instar larvae, staged by the morphology of the spiracles, were used for this study. Larval body-wall muscles were dissected in $\mathrm{Ca}^{+}$-free saline $(128 \mathrm{mM} \mathrm{NaCl}, 2 \mathrm{mM} \mathrm{KCl}$, $4 \mathrm{~mm} \mathrm{MgCl}$, 5 mм HEPES, $35.5 \mathrm{~mm}$ sucrose, 5 mм EGTA). Samples were fixed either in nonalcoholic Bouin's solution $[25 \mathrm{ml}$ formalin (from a $37.7 \%$ stock solution, Fisher), $5 \mathrm{ml}$ glacial acetic acid, $75 \mathrm{ml}$ saturated picric acid solution] or in paraformaldehyde fixative (4\% paraformaldehyde in $0.1 \mathrm{~m}$ phosphate buffer, $\mathrm{pH} 7.2$ ) for $1-2 \mathrm{hr}$. We found that immunoreactivity was substantially higher and more reliable in Bouin's fixed tissue.

After fixation, samples were washed 2-5 times (15 min each) in 0.1 $\mathrm{M}$ phosphate buffer, $(\mathrm{pH} 7.2)$ containing 0.2 or $0.3 \%$ Triton X-100 (PBT) Then they were incubated overnight in 1:200 anti-HRP (Sigma) diluted in PBT. After 3 washes with PBT, samples wcre incubated for $4 \mathrm{hr}$ in 1:20 goat anti-rabbit HRP-conjugated IgG (Cappel), washed 2 times in PBT, 1 time in $0.2 \mathrm{~m}$ Tris buffer $(\mathrm{pH}, 7.6)$, and reacted using diaminobenzidine (DAB, $5 \mathrm{mg} / \mathrm{ml}$ ) and $0.03 \% \mathrm{H}_{2} \mathrm{O}_{2}$.

Electron microscopy. Samples were dissected in $\mathrm{Ca}^{2+}$-free saline, as above, and fixed in modified Trump's fixative [ $1 \%$ glutaraldehyde, $4 \%$ paraformaldehyde, 0.1 м cacodylate buffer, $\mathrm{pH} 7.0$ (CB)] for $2 \mathrm{hr}$. Samples were then washed 3 times with $\mathrm{CB}$ and postfixed in $2 \% \mathrm{OsO}_{4}$ for 


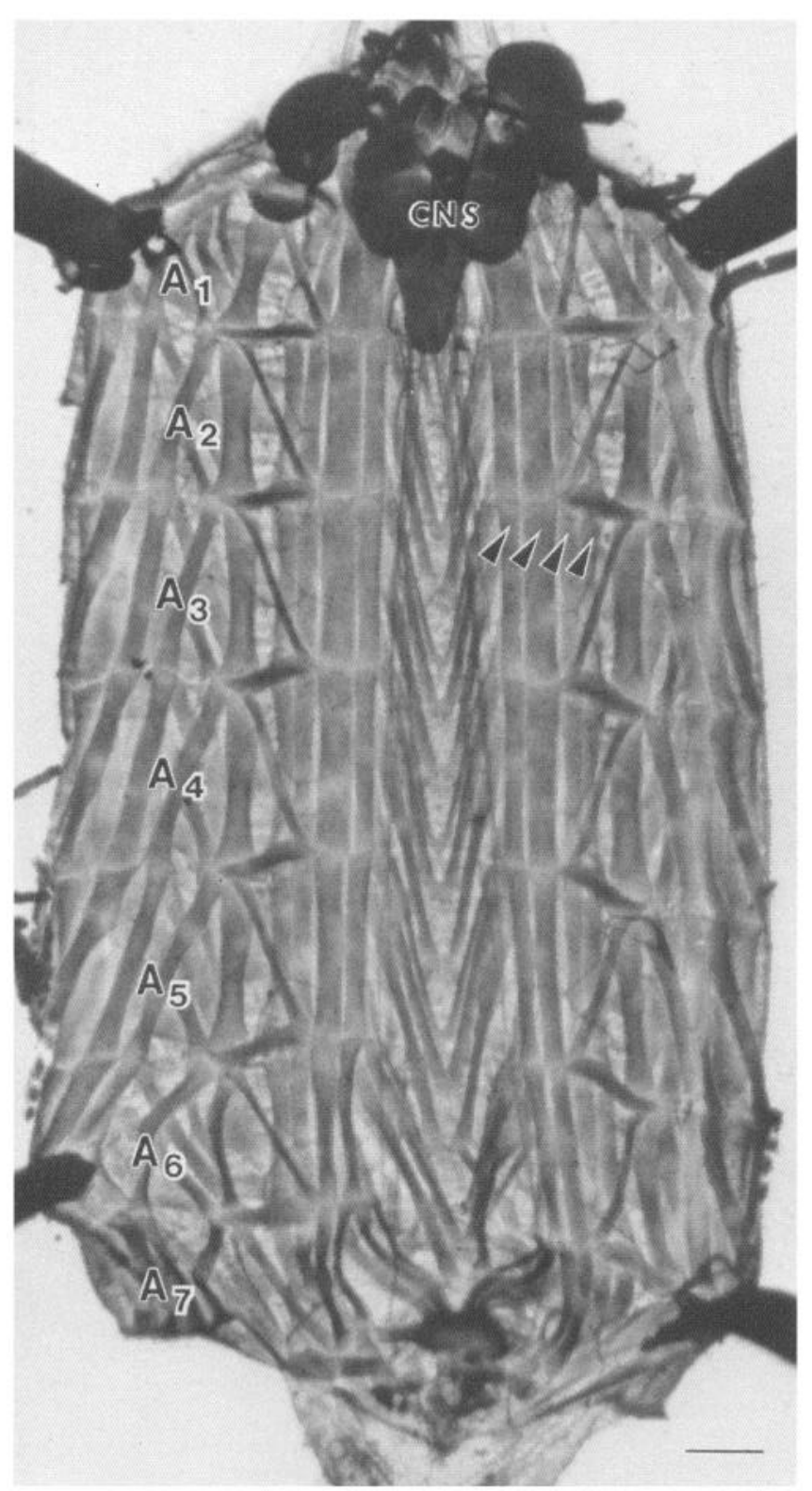

Figure 1. Toluidine-blue-stained preparation of body wall muscles of third-instar Drosophila larva. Arrowheads indicate (from left to right) longitudinal muscles $7,6,13$, and 12 of the third abdominal segment. $A 1-A 7$ indicate the abdominal segments $1-7$. Note the $C N S$ in the anterior (top) region. Scale bar $=200 \mu \mathrm{m}$.

$30 \mathrm{~min}$. After postfixation, samples were washed 3 times with $\mathrm{CB}$ and 3 times with distilled water and stained en bloc in $2 \%$ uranyl acetate for $1 \mathrm{hr}$. Samples were then dehydrated in an acetone series and embedded in Spurr's resin. Transverse thin sections were cut from muscles $6,7,12$, and 13 (identified in thick sections; nomenclature for muscle identification is according to Crossley, 1978), using a diamond knife. Grids were poststained in $4 \%$ uranyl acetate $(15-20 \mathrm{~min})$ and $1 \%$ lead citrate (5-8 min) and visualized using a Zeiss EM 10 microscope.

Toluidine-blue staining. To visualize the distribution of muscle nuclei, toluidine blue (TB) was used. Briefly, whole larvae were heat fixed for about $3 \mathrm{sec}$ in $60^{\circ} \mathrm{C}$ water. They were then dissected, stained for a few seconds in TB ( $6 \%$ borax, $1 \%$ boric acid, $1 \%$ toluidine blue), washed with water, and immediately photographed.

Electrophysiology. Extracellular recordings from body-wall muscles $6,7,12$, and 13 were made by a differential amplifier (DAM-5, WPI) and a capillary glass suction electrode with a tip diameter of $10-20 \mu \mathrm{m}$. The positive and negative leads were chlorided $\mathrm{Ag}$ wires. Electrical activity was recorded upon touching the muscle fibers with the glass electrode (no suction applied). Signals were bandpass filtered at $100 \mathrm{~Hz}$ and $10 \mathrm{KHz}$ and taped on a VCR recording system in conjunction with a pulse-code modulation unit (Neuro Data Instrument Corporation). All recordings were carried out in Drosophila normal saline (same as $\mathrm{Ca}^{2+}$-free saline but with $1.8 \mathrm{mM} \mathrm{CaCl}_{2}$ and no EGTA) at $19-20^{\circ} \mathrm{C}$.

\section{Results}

\section{Distribution of anti-HRP immunoreactive terminals in wild type}

The body-wall muscles of larvae are composed of identifiable muscle fibers arranged in a segmentally repeated pattern in the thoracic and abdominal segments (Fig. 1). For a description of this pattern and its development, see Campos-Ortega and Hartenstein (1985) and Johansen et al. (1989b). Immunocytochemical and physiological studies have demonstrated that most of the innervation is glutamatergic (Jan and Jan, 1976; Johansen et al., 1989a). However, a subpopulation of muscle terminals also shows proctolin or octopamine immunoreactivity (Anderson et al., 1988; Halpern et al., 1988).

Most electrophysiological studies in Drosophila larvae have been performed using a particular subset of the body-wall muscles, the abdominal ventral longitudinal muscles $6,7,12$, and 13 (nomenclature of Crossley, 1978). In this paper, we have centered on these muscles to study the morphology of motor terminals in mutants with altered excitability.

In order to visualize motor axon terminals, anti-HRP immunocytochemistry was used. In insects, the anti-HRP antibody binds to antigens exclusively located in neuronal membranes (Jan and Jan, 1982). The pattern of distribution of these terminals on each identified muscle fiber was characteristic. The description below and results of experiments in this paper were based on analyses of muscles $6,7,12$, and 13 at the third abdominal segment (Fig. 1). This description is in general agreement with the description of glutamatelike immunoreactivity at these muscles made by Johansen et al. (1989a, b).

Muscles 6 and 7. Anti-HRP immunoreactivity in these muscles was located in sparsely ramified branches in the lateral aspect of these muscles (Figs. $2 A, 3 A$ ). A branch that lies between muscles 6 and 7 gives rise to this innervation. Throughout this projection, as well as in the projections described below in muscles 12 and 13, enlargements of the neurites, or varicosities, are observed (Fig. 2). In muscles 6 and 7, most varicosities measure about 3-5 $\mu \mathrm{m}$ in diameter. However, some short ramifications show small varicosities in the range of $\leq 2 \mu \mathrm{m}$.

Muscles 12 and 13. At these more lateral muscles, a nerve branch contacts each fiber at its internal (visceral) face and gives off sparsely ramified branches that run anteriorly and posteriorly throughout the length of the muscle (Figs. $2 B, 3 A$ ). Near the initial contact of the nerve with the muscle (proximal terminals), most neurites show large varicosities (3-5 $\mu \mathrm{m})$. However, all distal neurites show varicosities of the small size $(\leq 2 \mu \mathrm{m}$; Fig. $2 B$ ). Although most branches emerging from the initial branch point were restricted to the domain of the particular muscle fiber, in many occasions, the distal portions of the branches extended for a few tens of microns into the adjacent segment, or into a neighboring muscle in the same segment (see, for example, Fig. 4A). This occurred more frequently in muscles of more anterior segments (30\% of muscle fibers in segment 2 , $21 \%$ of muscle fibers in segment $3,5 \%$ of muscle fibers in segment 6).

Motor axon terminals distribute in an anteroposterior gradient. Even though the general pattern of distribution of motor 

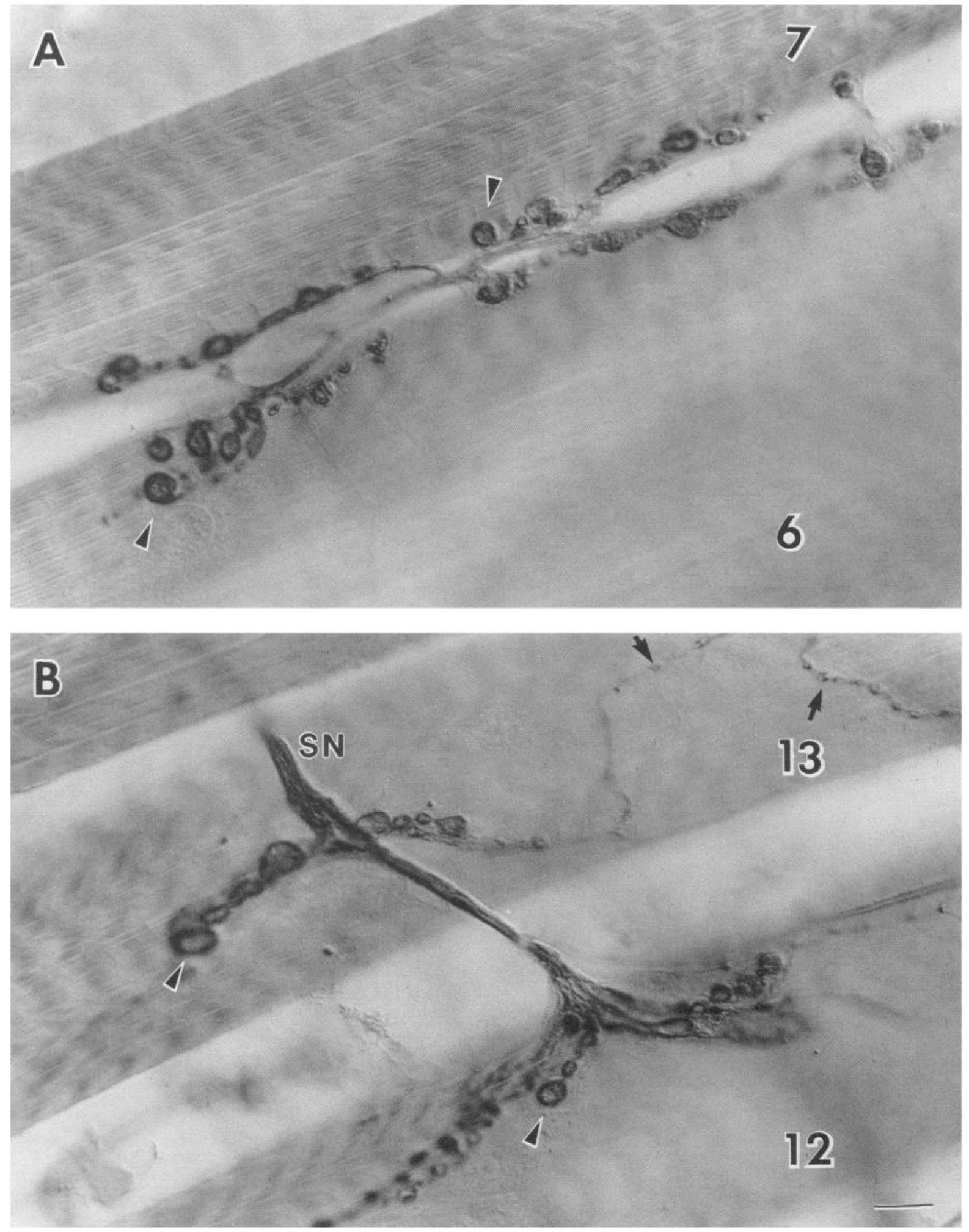

Figure 2. Innervation of muscles 6 and $7(A)$ and 12 and $13(B)$ as revealed by anti-HRP immunocytochemistry, visualized under Nomarski optics. Note the presence of prominent varicosities along neurites. Arrowheads point to the large-type varicosities, whereas arrows point to the small-type varicosities. $S N$, segmental nerve. Scale bar, $12 \mu \mathrm{m}$.

terminals is similar in all abdominal segments, it was noticed that anterior segments showed a higher degree of neurite ramification. The neurites of posterior segments displayed very little or no ramification, and the number of varicosities was also lower
(Fig. 4). This was particularly clear in muscles 12 and 13 from segment 6 , where on many occasions one of the distal projections was missing. There was also a continuous change in the size and width of muscle fibers: posterior muscles become longer 


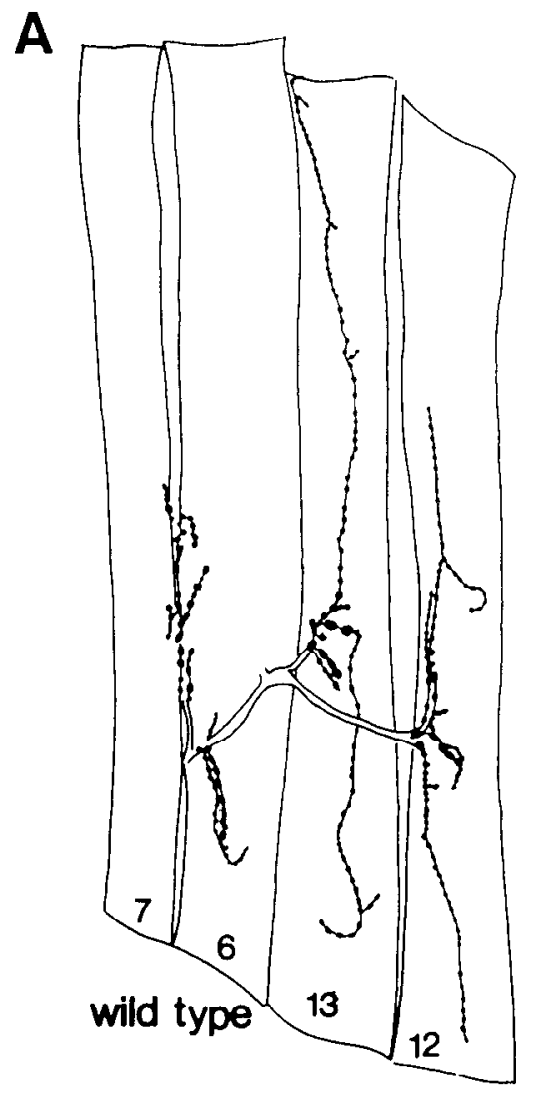

B

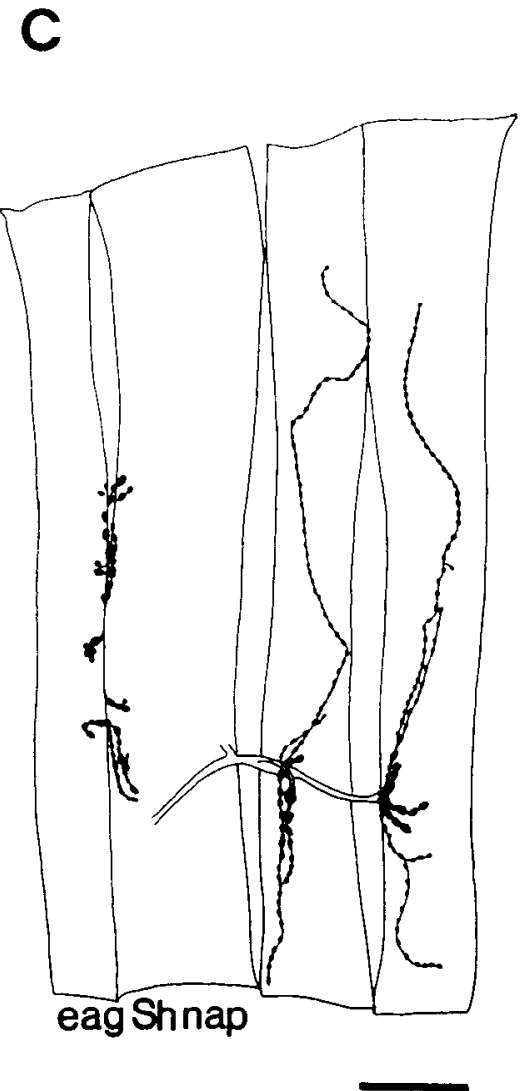

Figure 3. Camera lucida drawings of anti-HRP staining of axon terminals on muscles $6,7,12$, and 13 of wild-type $(A)$, eag ${ }^{4 P M} S h^{r K o r 2 o}$ double mutants $(B)$, and $e a g^{A P M} S h^{r K O / 20}$ nap ${ }^{t s}$ mutants $(C)$. Notice that, in eag'PM $S h^{r K O / 20}$, the extent of ramification of neurites in muscles 12 and 13 is increased. This alteration is suppressed by naps. Scale bar, $50 \mu \mathrm{m}$.

and thinner (see Figs. 1, 4A). Even after data were normalized using the surface area of the muscle fiber as drawn in camera lucida tracings (Fig. $4 A$ ), the anteroposterior difference persisted (Fig. 4B,C).

Several studies have suggested that varicosities are regions of synaptic contacts (see, for example, Lnenicka et al., 1986). In order to address this possibility, we studied transverse sections of these muscles at the electron microscopical level. One-micronthick sections were used to determine the presence of a varicosity. Then, the tissue was thin sectioned and stained with uranyl acetate and lead citrate. We analyzed 2 wild-type samples. We found that varicosities coincided with muscle sites showing synaptic terminals (Fig. 5; for descriptions of the ultrastructure of neuromuscular junctions in other insect species, see Osborne, 1975). These terminals were located in the peripheral sarcoplasm as invaginations into the muscle surface. Most terminals were characterized by the presence of $30-\mathrm{nm}$ diameter clear vesicles, as well as by a variable number of synaptic specializations in the presynaptic membrance (Fig. 5A). These vesicles were more concentrated in the region surrounding the synaptic specialization and seemed to be connected by a fibrous material. Terminals were separated from the postsynaptic membrance by a cleft of about $15-20 \mathrm{~nm}$. At the postsynaptic region, and surrounding the whole terminal, a well-developed subsynaptic reticulum was observed (Fig. 5A).
Hyperexcitable double mutants eag Sh show an increased number of branches and presumptive synaptic sites

In order to investigate the effect of mutations that increased excitability, we studied double-mutant combinations of 2 different alleles of eag and $S h$. We found that, in both eag $^{4 P M}$ innervation was altered (Fig. 3). The changes could be described as a substantial ramification of neurites throughout the muscle fiber. Analysis of these ramifications revealed that the number of higher order branches was particularly increased (Figs. 6, 7) In the wild type the number of primary branches was $7.2 \pm 0.2$ $(41 \%)$, the number of secondary branches was $9.3 \pm 1.1(54 \%)$, and the number of tertiary branches was $0.9 \pm 0.3(5 \%)$. No quaternary branches were observed in all 9 samples analyzed. In eag $^{\prime} S h^{K S 133}$ the number of primary and secondary branches was $8.1 \pm 0.6(31 \%)$ and $11.8 \pm 1.1(46 \%)$, respectively, and did not differ significantly from the wild type. In contrast, the number of tertiary $(4.7 \pm 0.5,18 \%)$ and quaternary $(1.3 \pm 0.4$, $5 \%)$ branches was significantly increased $(p<0.05)$. In addition, the number and, in some cases, the density, of varicosities in the neurites was also increased (Fig. 8).

The increase in the number of branches and varicosities was most noticeable in neurites containing predominantly the smallsized varicosities. Therefore, the effect was particularly clear in muscles 12 and 13 (Figs. 6, 8A). However, the same pattern of 
alterations, though less dramatic, was observed in muscles 6 and 7 of eagl $S h^{K S / 33}$ mutants. In these muscles $(6,7)$, only the number of varicosities was analyzed, because the degree of ramification of neurites was difficult to quantify (Fig. $8 B$ ). No changes in the segmental or muscle specificity of the innervation were found in this and all other mutants analyzed in this study.

Only a slight but statistically significant decrease in the extent of branching was observed in temperature-sensitive nap ${ }^{t s}$ larvae, when reared at permissive temperature (Figs. $7 C, 9$ ). However, $n a p^{t s}$ in combination with eag ${ }^{A M} S h^{\text {rKor20 }}$ completely reversed the eag $S h$ mutant phenotype in the body-wall motor axons (Figs. $3 C, 7 B, 8$ ). In contrast, in eag ${ }^{P M}$ para ${ }^{t s l} S h^{r K O I 20}$ mutants reared at permissive temperature, the pattern of arborization of motor axons remained similar to that observed in eag Sh (Fig. 8). Only a slight but statistically insignificant increase in the number of branches and varicosities was observed in the single mutants eag and Sh (Fig. 9).

In vertebrate skeletal muscles, it has been noticed that, during synapse formation, myonuclei accumulate under the nerve terminal, in positions that coincided with clusters of ACh receptors (Nakai, 1968; Kelly and Zacks, 1969). Induction of ACh-receptor cluster formation elicited nuclei movements towards the newly formed cluster (Englander and Rubin, 1987). In Drosophila body-wall muscles, glutamate receptors seem to localize in regions of the muscle that are apposed to neurites (Johansen et al., 1989a.). Therefore, it was important to ascertain if the changes in distribution of varicosities in hyperexcitable mutants were correlated with changes of nuclear distribution. As in most muscles, the body-wall muscles of Drosophila larvae are polynucleated. These nuclei are distributed superficially in the internally facing (visceral) sarcolemma in a fashion characteristic for each muscle type. In muscles 7 and 13 of the third segment, for example, they distribute in a single row along the anteroposterior axis of the fiber (Fig. 10). In muscle 6, in contrast, nuclei are distributed in 2 alternating rows. In muscle 12 , most nuclei were concentrated in the anterior half of the muscle fiber, often surrounding the region of contact of the nerve with the muscle fiber (Fig. 10). The distribution of nuclei in each segment was not identical. For example, in more posterior segments, the double row apparent in muscle 6 was transformed to a single row of nuclei. No change in the distribution or number of these nuclei was detected in any of the excitability mutants analyzed in this study.

\section{Other mutants with increased excitability show alterations similar to eag $\mathrm{Sh}$}

Similar to the 2 eag $S h$ mutants, the appearance of nerve terminals in $H k^{l} e a g^{l}$ larvae was also altered. Again, the alteration was readily apparent in counts of the number of branches and varicosities, which showed an increase similar to that observed in eag $S h$ mutants (Fig. 11).

Because the molecular identity of the eag and $H K$ gene products is unknown, we wanted to address the question of whether increasing excitability by using other better-defined mutations would also produce the same changes in the morphology of motor axons. Stern et al. (1990) have demonstrated that increasing the number of normal para genes by introducing duplications of the gene ( $D p$ para $\left.{ }^{+}\right)$has 2 prominent effects. It suppresses the temperature-sensitive paralysis of nap ${ }^{i s}$, presumably by restoring the $\mathrm{Na}^{+}$channel density, and it enhances the leg-shaking phenotype of $S h^{K S 133}$, resulting in a behavioral phenotype similar to $\mathrm{eag}^{I} S h^{K S 133}$.
A
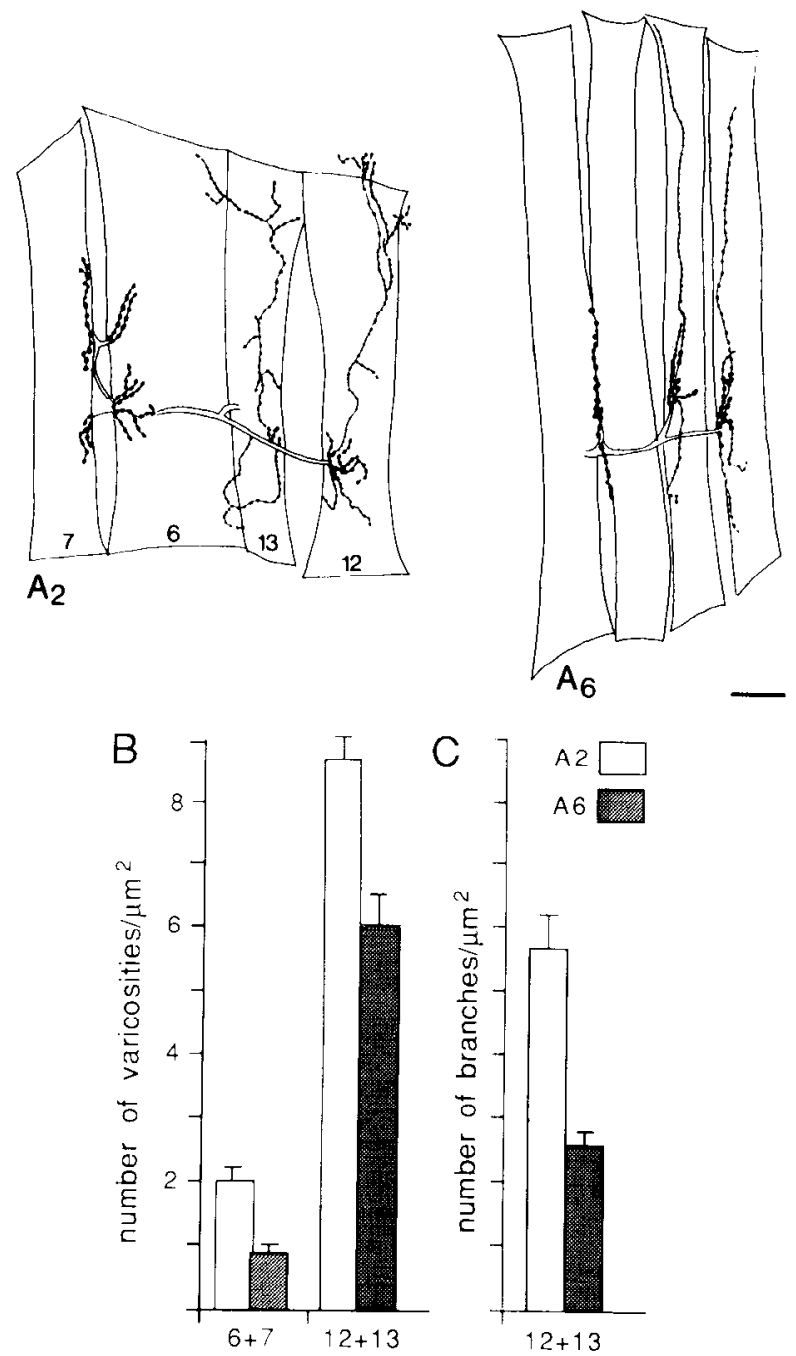

Figure 4. Anteroposterior gradient in extent of branching and number of varicosities of muscles $6,7,12$, and 13. $A$, Camera lucida drawings of muscles $6,7,12$, and 13 of an anterior segment $(A 2)$ and of a posterior segment (A6). Scale bar, $50 \mu \mathrm{m} . B$ and $C$, Number of branches and varicosities in muscles $6,7,12$, and 13 in $A 2$ and $A 6$. B, Number of varicosities per unit area $\times 10^{3}$ in muscles 6 and 7 and 12 and 13. $C$, Number of branches per unit area $\times 10^{4}$ in muscles 12 and 13. Data are expressed as mean $\pm \mathrm{SEM} ; n=10$. Note the decrease in both the number of varicosities and branches in the posterior segment.

We examined nerve terminals of male larvae that contained at least 1 extra copy of the normal para ${ }^{+}$gene $\left[l^{D 23}: D p(1: 4) r^{+} f\right]$. In addition, we analyzed a strain containing the mutation $S h^{K S 133}$ in addition to the $D p$ para $^{+}\left[D f(1) r^{D 17} S h^{K S 133} ; D p(1: 4) r^{+} f\right]$. We found that, in both strains, the number of branches and varicosities was significantly increased, but to a lesser extent than that of eag Sh or Hk eag mutants (Fig. 11). Closer analysis of the data revealed a high variability not observed in any of the other strains analyzed. There appeared to be a group of samples with a phenotype similar to wild type, and a group of samples similar to eag Sh or Hk eag (Fig. 11). This could be the result of either variable penetrance or a different number of $\mathrm{para}^{+}$gene copies (see Discussion).

\section{Endogenous pattern of activity in the body-wall muscles}

Many studies of eag, $S h$, and $H k$, as well as of their doublemutant combinations, have shown electrophysiological char- 

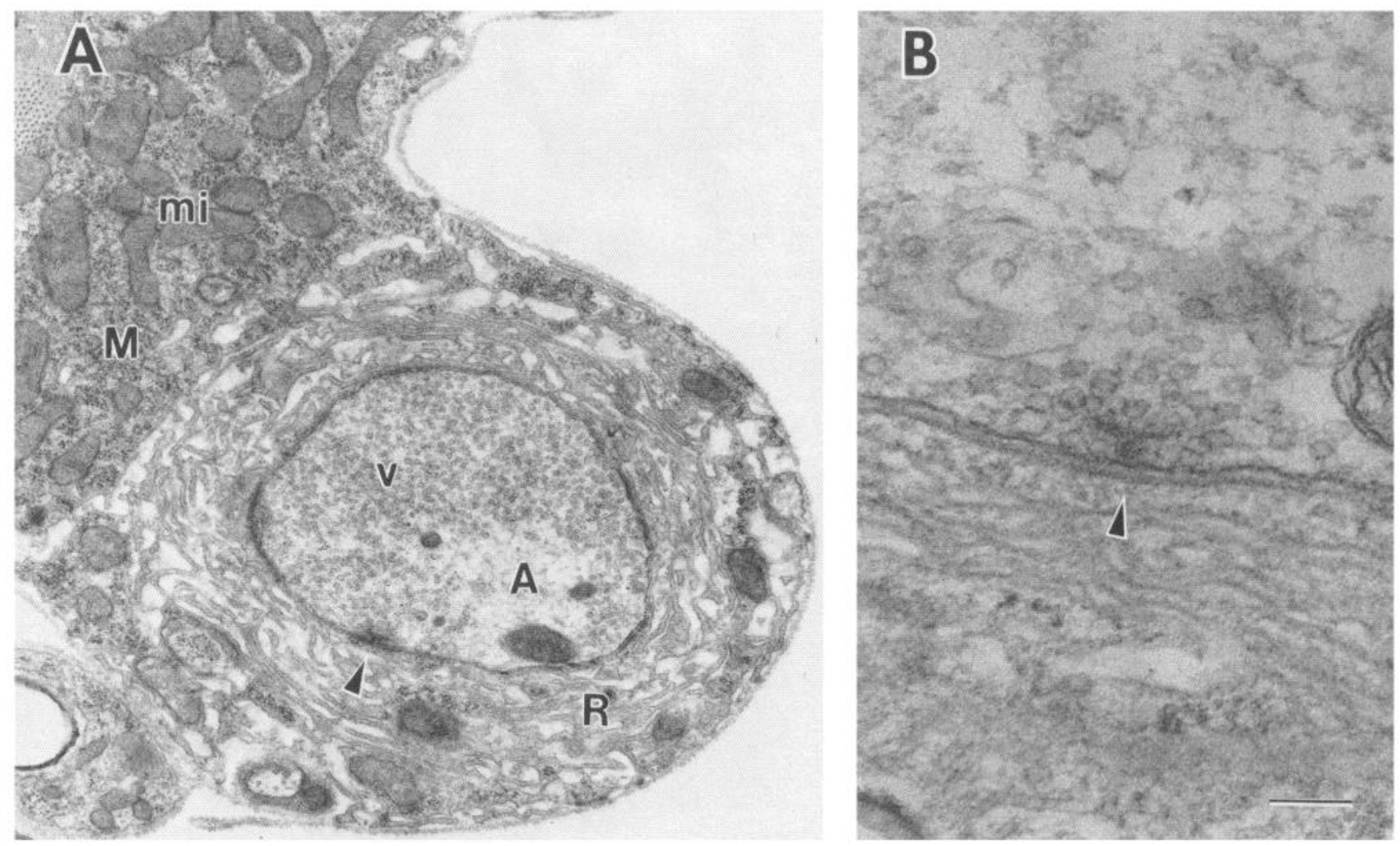

Figure 5. Electron micrographs of varicosities. $A$, A lower-magnification view showing an axon terminal $(A)$ containing 30 -nm clear vesicles $(v)$ and a region of presumptive synaptic contact (arrowhead). $M$, muscle; mi, mitochondria; $R$, subsynaptic reticulum. $B$, Higher-magnification view of a synaptic region showing clear synaptic vesicles as well as an electron-dense body typical of insect neuromuscular synapses (arrowhead). Scale bar: $0.6 \mu \mathrm{m}, A ; 0.1 \mu \mathrm{m}, B$.

acteristics consistent with hyperexcitable behavioral phenotypes. However, most, if not all, of these studies have been conducted under conditions where the input from the CNS had been severed. In addition, many of the hyperexcitable phenotypes have been studied at low calcium concentrations ( $\mathrm{Ga}$ netzky and $\mathrm{Wu}, 1983$ ), at which reduced muscle contractions present less technical problems for intracellular EJP recordings. As a result of the striking changes in the morphology of axon terminals observed in these mutants, we were interested in verifying nerve hyperexcitability in these mutants at normal calcium concentration and with normal CNS inputs. We recorded from the muscles in a semi-intact preparation with the nerve connection between the CNS and the muscle left intact. Under these conditions, these supercontracting muscles contract considerably, making intracellular recordings technically very difficult. However, we found that the CNS-generated pattern as reflected by the muscle activity could be recorded extracellularly for 5-20 min.

Figure 12 shows the typical pattern of activity observed in the wild type, which was composed of a rhythmic pattern of bursting activity. Each burst consisted of a train of nerve-evoked spikes in the muscles. These spikes could correspond to action potentials at the muscle and/or to EJPs (Yamaoka and Ikeda 1988; M. Gho, personal communication). We believe that these spikes were nerve evoked and not spontaneous myogenic activity because they were completely blocked by TTX. Inward currents in these muscles are carried by $\mathrm{Ca}^{2+}$ (Gho and Mallart, 1986; Singh and Wu, 1989), but we observed no such spikes in wild-type and mutant larvae at normal $\mathrm{Ca}^{2+}$ concentrations in the absence of CNS input. Periods of bursting activity, usually lasting on the order of minutes, were followed by periods of quiescence. Great variability was found from preparation to preparation regarding duration of bursts, frequency of spikes within a burst, duration of periods of bursting activity, and duration of periods of silence. Therefore, we did not attempt to quantify further these parameters of the pattern. Figure $13 \mathrm{~A}$ shows the bursting pattern observed in 3 different wild-type preparations. A common feature of most wild-type patterns recorded was their predominantly bursting nature.

In eag ${ }^{A P M} S h^{r K O I 20}$ mutants, bursting activity was also observed in the majority of the muscle fibers. However, in contrast to the wild type, periods of strong tonic activity, not organized into bursts, were also observed. This tonic activity was either superimposed on the bursting activity or observed alone. Figure $13 B$ shows representative examples of patterns observed in 3 different $e a g^{A P M} S h^{r K O I 20}$ preparations.

In order to characterize the distribution of patterns in these mutants, muscle activity observed in a period of 5-20 min was classified as follows.

Bursting (B): at least 3 bursts of spikes in approximately a 3-min period; all spikes grouped into bursts.

Bursting with some tonic component $(\mathrm{B} / \mathrm{T})$ : spikes mostly grouped in bursts, but a low level of tonic activity (spikes not grouped into bursts) also observed.

Mixed tonic and bursting activity $(\mathrm{T}+\mathrm{B})$ : Strong tonic nonbursting activity accompanied by periods of bursting activity, or the tonic activity seems to be superimposed on bursting activity.

Tonic (T): Activity is purely tonic with no clear signs of bursting organization. 

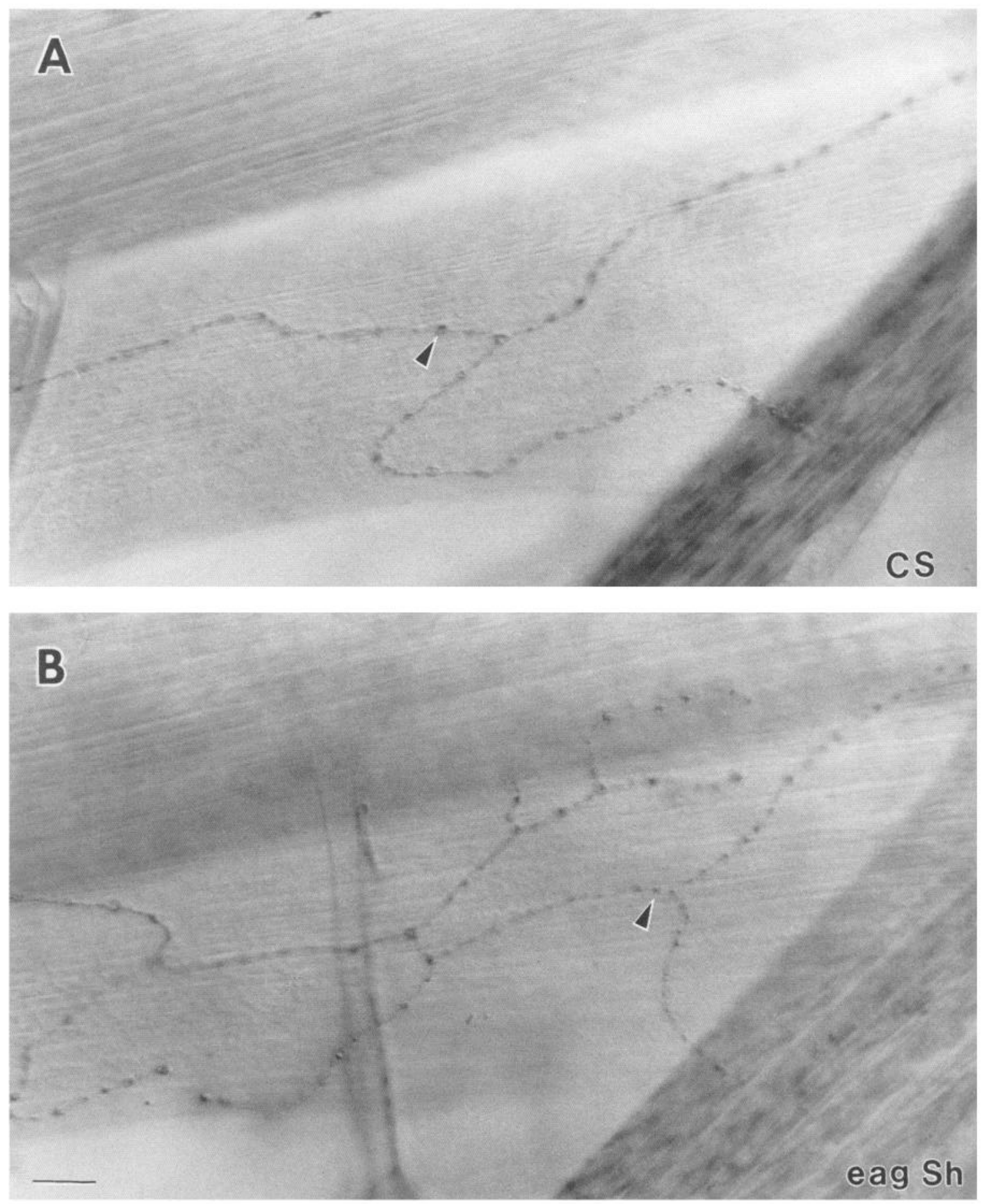

Figure 6. HRP immunoreactivity of neurites containing small-type varicosities (arrowheads) in $C S(A)$ and $e a g^{l} S h^{\kappa S I 33}(B)$ in distal axonal region of muscle 12. Notice the increased ramification of neurites in $\mathrm{eag}^{I} \mathrm{Sh}^{\kappa S / 33}$. Scale bar, $12 \mu \mathrm{m}$.

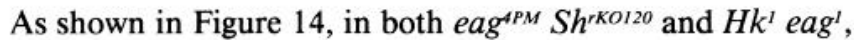
there is an increase in the percentage of fibers that show some level of activity not grouped into bursts (categories B/T and $\mathrm{T}+\mathrm{B})$. This is in contrast with wild-type muscle fibers where activity is mostly organized into bursts (category B). These results show that, in addition to the increased neurotransmitter release that is observed in these hyperexcitable mutants $(\mathrm{Ga}-$ netzky and $\mathrm{Wu}, 1983)$, there are also alterations in the pattern of activity of the motoneurons. However, we found that in
$S h^{K S 133} \mathrm{Dp} \mathrm{para}{ }^{+}$mutants, though there was a dramatic increase in the amplitude of EJPs (Stern et al., 1990), the pattern of activity at the muscles was very similar to wild type (Fig. 14D).

In the morphological analysis of nerve terminals, we found that $n a p^{t s}$ could suppress the increased number of branches and varicosities of $e a g^{A P M} S^{r} h^{r O I 20}$. In addition, $n a p^{i s}$ has been found to suppress some behavioral and physiological abnormalities of eag and Sh (Ganetzky and Wu, 1982a,b, 1983). Therefore, it was relevant to investigate whether the abnormalities in the 
<smiles>[B]</smiles>

Figure 7. Number of primary, secondary, tertiary, and quaternary branches in muscles 12 and 13 in wild type $(n=9)$ and $e a g^{4 P M} S^{\text {rKOI20 }}(n=9$; $A)$, eag ${ }^{4 P M} S h^{\text {rKOI20 }}$ nap $^{\prime s}(n=8 ; B)$, and $n a p^{t s}(n=7 ; C)$. Data are expressed as mean \pm SEM. Note that the increase in branching observed in eag ${ }^{4 P M} S h^{r K O I 20}$ is due to an increase of higher-order branches. Also notice that higher-order branches are reduced in nap ${ }^{s}$ mutants.

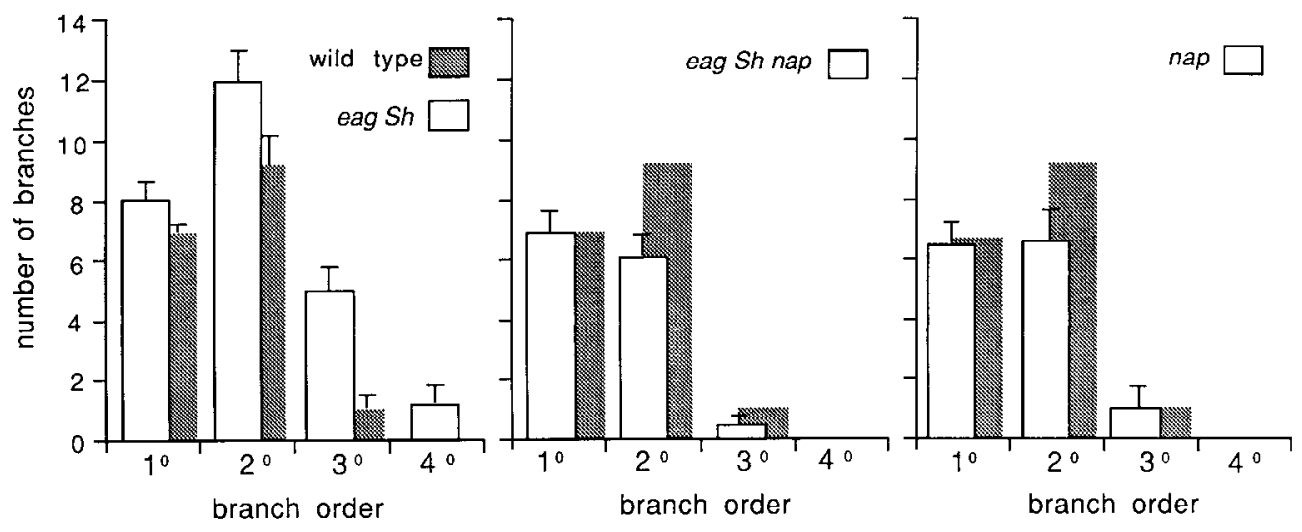

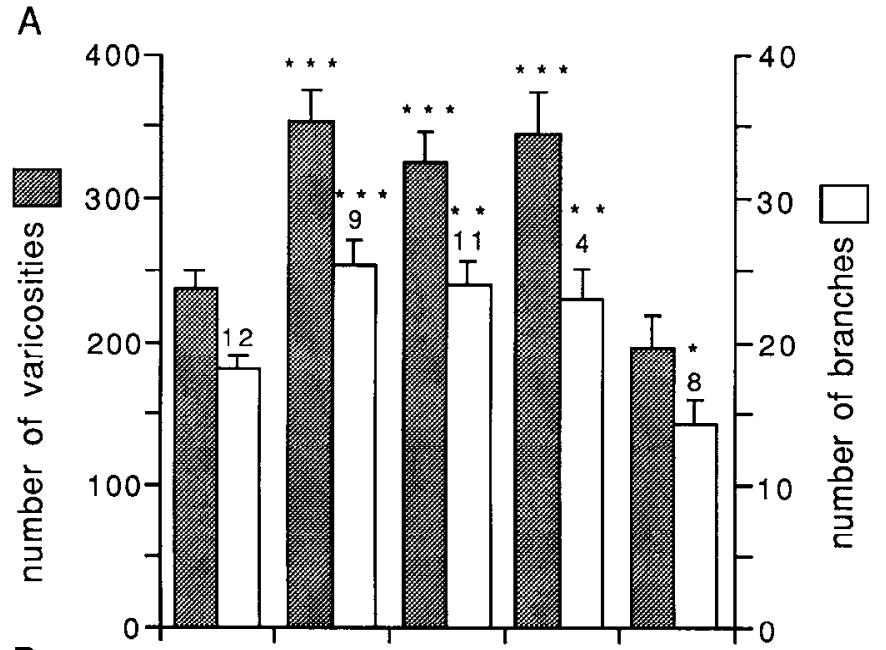

B

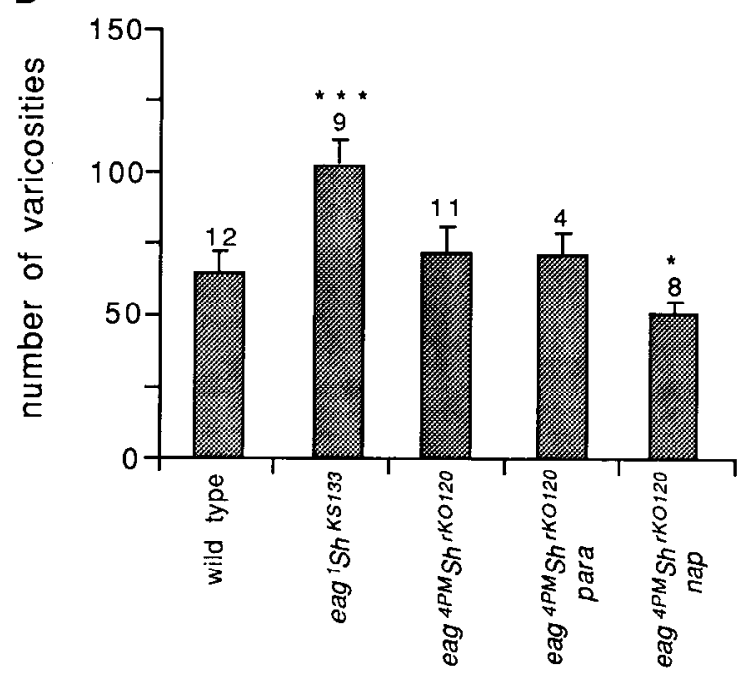

Figure 8. Graphical representation of number of varicosities and total number of branches in muscles 12 and $13(A)$ and in muscles 6 and 7 $(B)$. Note the increase in the number of varicosities in 2 different eag $S h$ double mutants. nap $p^{s s}$, unlike para ${ }^{t s l}$, in combination with eag $S h$, completely reversed this altered phenotype. Data are expressed as mean \pm SEM. The number of samples is indicated near the error bars. Means were compared to wild type using the Student's $t$ test. *, $p<0.05$; **, $p<0.005{ }^{* * *}, p<0.0005$. pattern of activity of motor axons could also be rescued by naps. As shown in Figures $13 C$ and 14, the hyperexcitable pattern of activity observed in $e a g^{4 P M} S h^{r K O I 20}$ was only partially suppressed by $n a p^{s}$. While there was an increase in the number of fibers with purely bursting activity, and a decrease in the number of fibers showing strong tonic activity $(\mathrm{T}+\mathrm{B})$, the distribution of activity types was not completely like the wild type. In most muscle fibers, bursting activity was readily apparent. However, in many fibers, a low level of abnormal tonic activity was also observed (Fig. 14).

In the single mutants $n a p^{t s}$ and $e a g^{A M M}(n=12$ and 11 fibers, respectively; data not shown), the distribution of activity types was almost as the wild type, though in eag ${ }^{4 P M}$, there was a slight increase in the number of muscle fibers that displayed a low level of tonic activity in addition to the bursting activity (B/T type).

\section{Discussion}

In this article, we report the effects of mutations that alter neuronal excitability on the morphology of motor axon innervation.

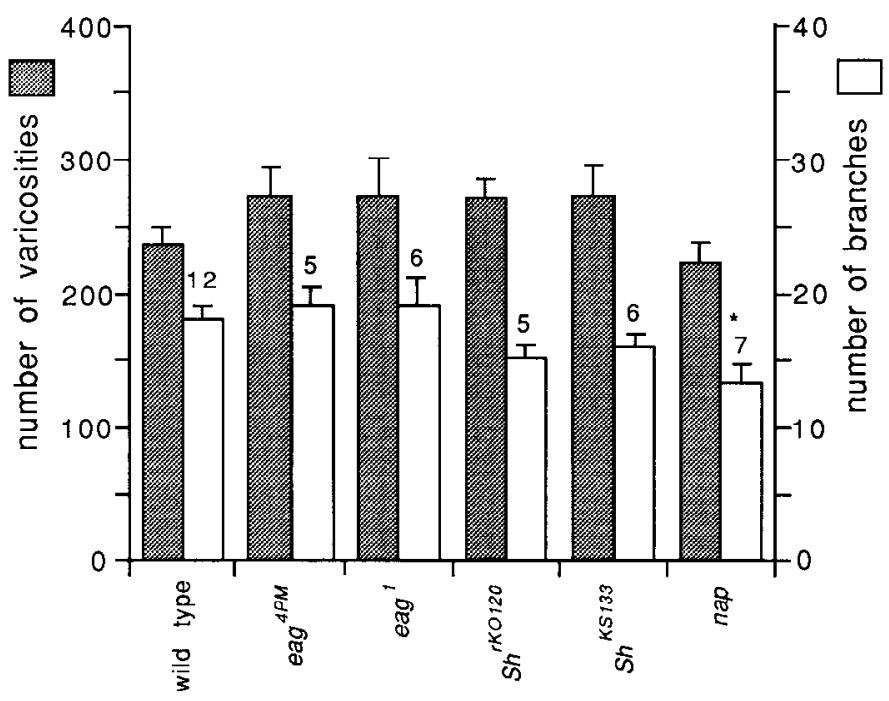

Figure 9. Number of branches and varicosities in single mutants. Data expressed as mean \pm SEM. The number of samples is indicated near the error bars. ${ }^{*}, p<0.05$. 


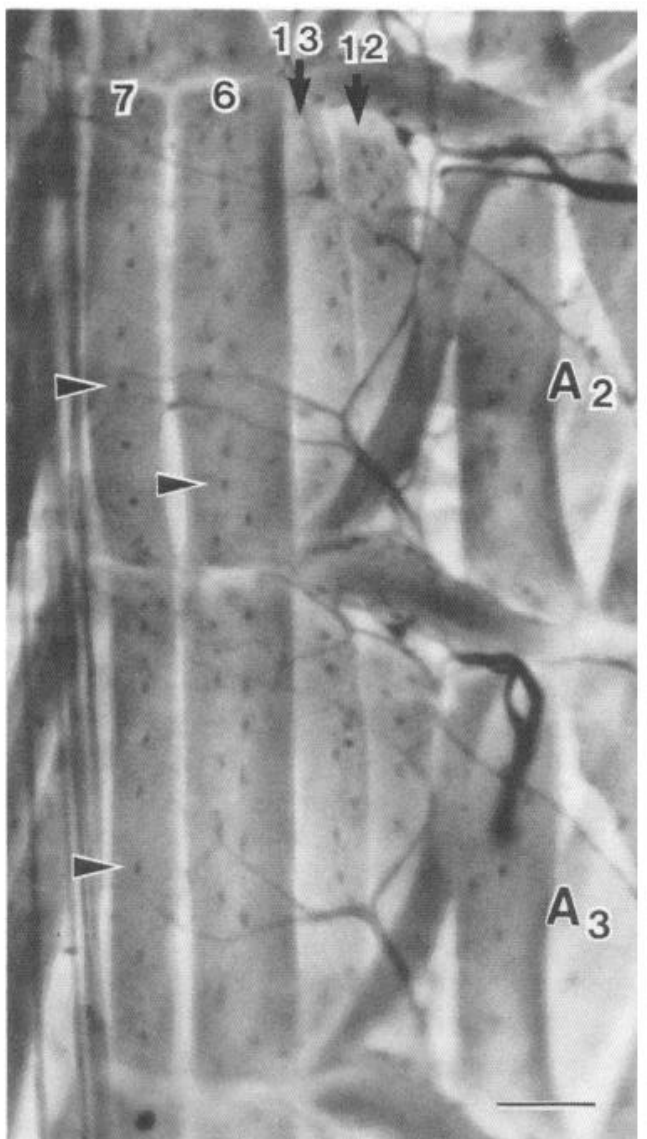

Figure 10. Distribution of nuclei (arrowheads) in muscles 6, 7, 12, and 13 of the abdominal segments $A 2$ and $A 3$, as revealed by toluidine-blue staining. Scale bar, $80 \mu \mathrm{m}$.

We used the body-wall muscles of Drosophila larvae because their physiology, anatomy, and development have been well characterized (Ganetzky and Wu, 1986; Johansen et al., 1989b). Anti-HRP staining of axon terminals revealed that they displayed varicosities that could be classified into 2 populations according to their size (small type and large type; see also Johansen et al., 1989a). Ultramicroscopical analysis revealed that varicosities coincided with synaptic sites. However, because we did not serially section the tissue, we do not know whether varicosities are exclusive sites of synapses or whether there are synapses at other neuritic sites, as well. In crustacean neuromuscular junctions, it has been shown that, while varicosities are the region where most ultrastructural synaptic features are found, these are also seen at extravaricosity sites (Lnenicka et al., 1986). Studies are in progress to determine if the same is the case in Drosophila.

We found that, even though the distribution of axon terminals seemed to be characteristic for each identifiable muscle fiber in different segments, there were clear differences among body segments. The degree of branching as well as the number of varicosities decreased in more posterior segments. These intersegmental differences could be the result of a developmental gradient at a particular period of synaptogenesis. Alternatively, it could be the result of functional differences, for example, an anteroposterior gradient in the levels of activity of neuromuscular junctions, which in turn could result in variations in the size of the projection and presumably in the number of synaptic sites.

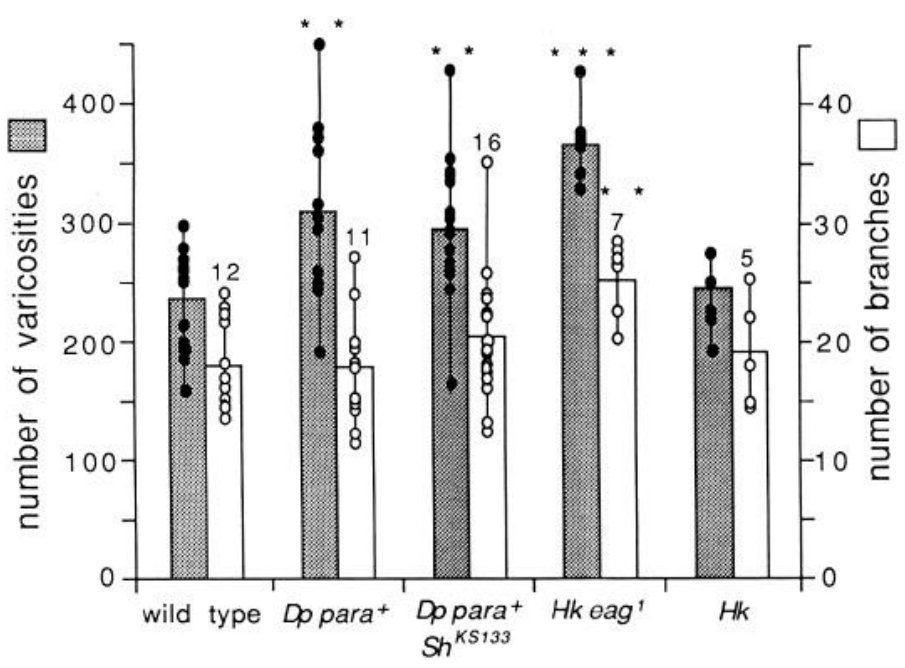

Figure 11. Number of branches and varicosities of muscles 12 and 13 in CS, Dp para ${ }^{+} S^{\kappa S / 3 s} \mathrm{Dp} \mathrm{para}^{+}, H k \mathrm{eag}^{\prime}$ and $H k$. Each point in this graph corresponds to counts in an individual sample. Notice the variability of $D p$ para $^{+}$and $D p$ para $^{+} S h^{\kappa S I 33}$ data. ${ }^{* *}, p<0.005 ;{ }^{* * *}, p<$ 0.0005 .

We centered our study exclusively on the third abdominal segment.

An interesting observation is that each segment is mainly innervated by the corresponding segmental nerve, but that terminal neurites can cross the segmental boundaries and innervate the distal portions of muscles of adjacent segments. This implies that there is not strict segmental specificity for the body-wall muscle innervation.

\section{Influence of activity on motoneuron terminal arbors}

Comparisons of wild-type axon terminals with terminals of several hyperexcitable mutants revealed a significant increase in

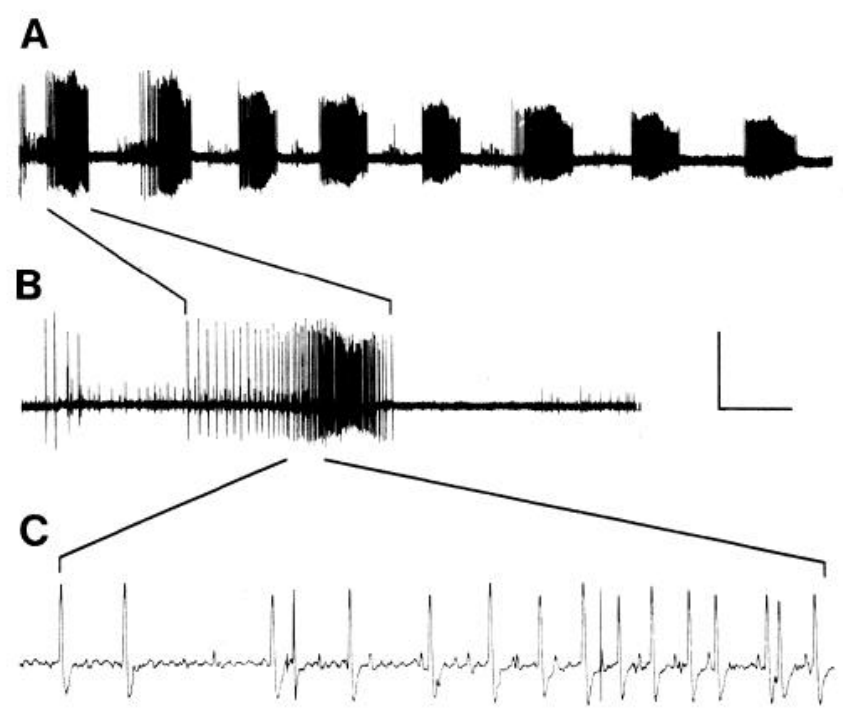

Figure 12. Extracellular recordings of CNS-evoked responses in larval body-wall muscle 6 . Similar activity was observed in muscles 7,12 , and 13. In this preparation, connections between muscles and CNS were left intact (see Fig. 1). Recordings were carried out at $19-20^{\circ} \mathrm{C}$ in normal saline. Vertical bar, $150 \mu \mathrm{V}$; horizontal bar, $5 \sec$ in $A, 1 \sec$ in $B, 50$ msec in $C$. 
A

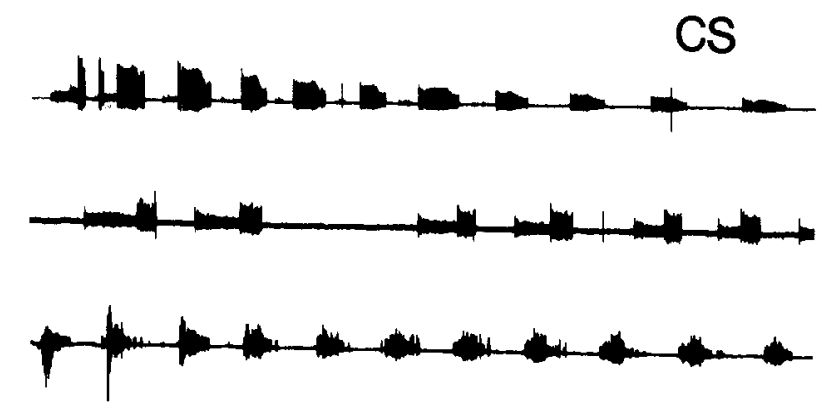

B
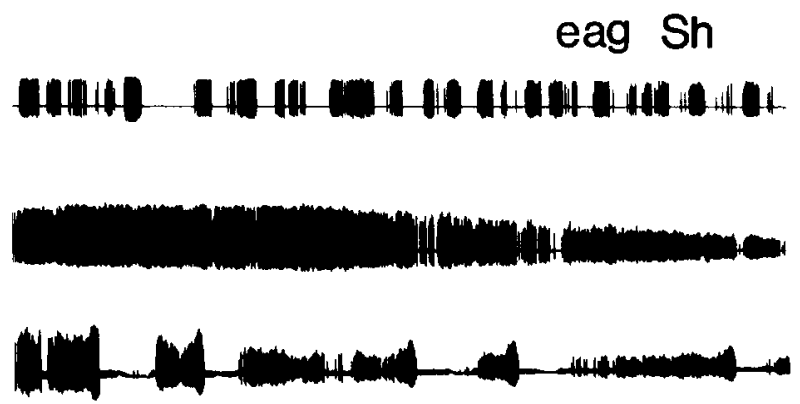

C
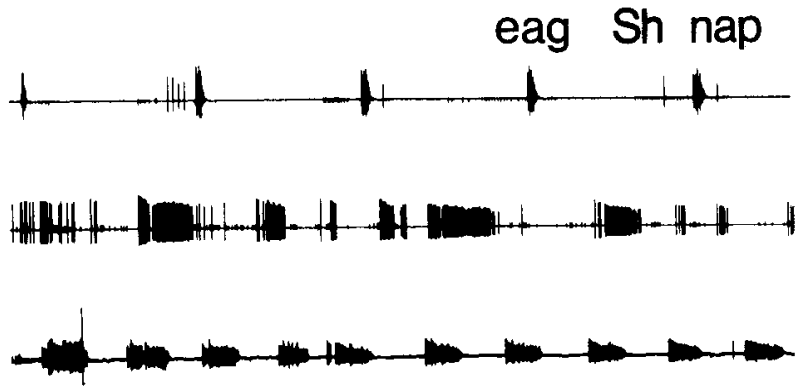

$\overline{20 s}$

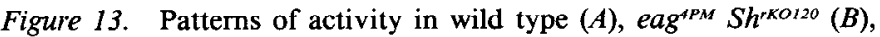
and eag ${ }^{A P M} S h^{r K O 120}$ nap $^{t s}(C)$. Each trace in $A, B$, and $C$ is a recording of a different larval preparation representing a typical pattern observed. Notice that in wild type, CNS-driven spikes are grouped in bursts. In contrast, in $e a g^{4 P M} S h^{r K O I 20}$, tonic activity is dominant, though it is accompanied by periods of bursting activity. Most eag $g^{A M} S h^{r K O I 20}$ nap ${ }^{t s}$ preparations show a bursting activity similar to wild type. However, a large proportion of muscle fibers in this genotype still show a low degree of abnormal tonic activity.

the extent of branching, in particular, higher-order branches, and an increase in the number of varicosities. This was most dramatic in the double mutants eag $S h$ and $H k$ eag, and to a lesser extent, in $D p$ para ${ }^{+}$and $S h D p$ para ${ }^{+}$. None of the single mutants eag, $S h$, or $H k$ showed statistically significant difference from the wild type. It is interesting to note that the mutants eag $S h, H k$ eag, Dp para ${ }^{+}$, and $S h D p$ para $^{+}$have many common physiological and behavioral abnormalities related to hyperexcitability (Ganetzky and Wu, 1983; Stern and Ganetzky, 1989; Stern et al., 1990). However, the mechanism by which they increase excitability is different. For example, eag $S h$ mutants confer hyperexcitability by decreasing potassium currents $\left(I_{A}\right.$ and $I_{K}$ ), whereas $D p$ para $^{+}$mutants produce an hyperexcitable phenotype presumably by increasing the number of sodium channels (Stern et al., 1990).

Even though the number of varicosities and branches in both Dp para and $S h$ Dp para ${ }^{+}$samples was significantly higher than the wild type, we observed great variability in the morphological data. There appeared to be some samples very similar to the wild type, and others with a phenotype similar to eag $S h$ or $H k$ eag. This variability is possibly related to the uncertainty in the number of duplicated $\mathrm{para}^{+}$genes present in the two strains used $\left[l(1) l^{D 23} ; D p(1,4) r^{+} f\right.$ or $\left.D f(1) r^{D 23} ; D p(1,4) r^{+} f^{+}\right]$. Their genetic compositions assure that at least 1 extra copy of para (in addition to the one normally present on the $\mathrm{X}$ chromosome) will be present in males (Stern et al., 1990). This is so because this duplication covers $l(1) l^{D 23}$ and $D f(1) r^{D / 7}$ that are otherwise lethal. However, there could be either 1 extra copy of the para ${ }^{+}$ gene in heterozygotes or 2 extra copies in flies homozygous for $D p(1,4) r^{+} f$. It is not possible to distinguish larvae of these 2 genotypes.

The fact that hyperexcitability derived from different molecular defects in eag $S h, H k$ eag, $D p$ para ${ }^{+}$, and $S h D p ~ p a r a^{+}$ produces similar morphological alterations indicates a possible activity-dependent mechanism that could regulate the growth or maintenance of the motor terminals. Similar observations have been reported in the neuromuscular synapses of crustaceans (Lnenicka et al., 1986), where increasing the level of activity by chronic stimulation of a motor axon also produced an increase in the number of varicosities at the terminals.

Further evidence consistent with our hypothesis of activitydependent morphological change is that the reduced excitability caused by napts reversed the effect of eag $S h$ on motor axon terminals. This mutant has been shown to reverse hyperexcitable phenotypes of eag, $S h$, and $D p p a r a^{+}$physiologically and behaviorally (Ganetzky and Wu, 1985; Stern et al., 1990), presumably by decreasing the expression of the $\mathrm{para}^{+}$gene, thereby decreasing the number of sodium channels (Kauvar, 1982; Jackson et al., 1984). It is interesting to note that the nap ${ }^{s s}$ mutation alone shows a decrease in the degree of branching in comparison to the wild type. This could indicate that reduced excitability generates effects opposite to those caused by hyperexcitability in motor axon terminal morphology. In contrast to nap ${ }^{t s}$, paratst did not reverse the eag $S h$ phenotype. This is not surprising because no physiological defects have been found in para $^{t s}$ when reared and tested at room temperature (Wu and Ganetzky, 1980; Kauvar, 1982; Jackson et al., 1984).

An intriguing observation is that the changes observed in the number of higher-order branches and varicosities were most dramatically expressed in neurites containing the smaller type of varicosities. At present, it is not known whether there is a functional difference between the larger- and smaller-type varicosities. Studies are in progress to determine if the 2 types can be differentiated ultrastructurally. A speculation that can be made is that neurites containing the smaller type of varicosities are plastic portions of motor terminals. These regions could be the sites at which the size of the projection and the number of synapses are regulated, for example, during the dramatic growth that the muscles undergo throughout the larval stages.

Our results are in contrast with what was observed by Burg and $\mathrm{Wu}(1986,1989)$ in sensory neurons of adult Drosophila. Genetic mosaics were generated in which a single sensory-bristle complex was genotypically eag $S h$ or para $^{t s l}$ nap ${ }^{t s}$. However, analysis of the morphology of the sensory neuron dendritic arborization revealed no obvious abnormality with either mutant. 

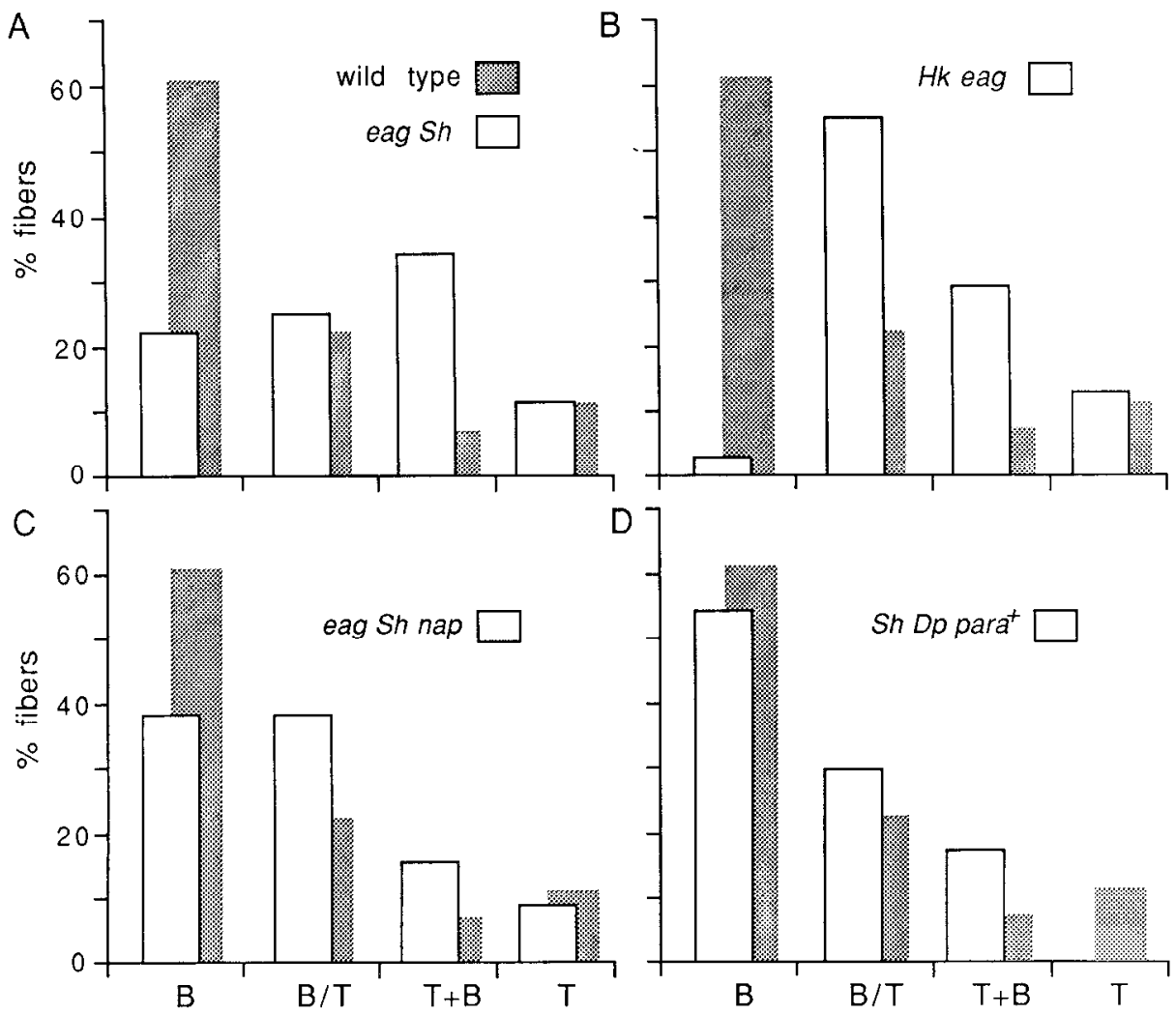

Figure 14. Distribution of muscle fibers with bursting $(B)$, tonic $(\mathrm{T})$, or a combination of both patterns of activity $(B / T$ or $T+B$; see text) in wild type $\left(n=35\right.$ fibers) and $e a g^{4 P M} S h^{\text {KOIIZO }}(n=$ 34 fibers; $A$ ), $H k^{l}$ eag $^{\prime}(n=32$ fibers; $B), e^{a g^{4 P M}} S^{\text {rKOI20 }}$ nap $^{t s}(n=32$ fibers; C), and $S h^{K S / 33} \operatorname{Dppara}^{+}(n=30$ fibers; D).

Several alternative explanations for these results can be made. First, it is possible that activity-dependent changes of neural development are restricted to a selected population of neurons. In fact, sensory receptors are epithelial in origin and, thus, may differ from motoneurons derived from central neuroblasts. A second possibility is that, in order to produce changes in neuronal morphology and synaptogenesis, it is necessary for the mutation to elicit changes in both the presynaptic and postsynaptic sites. In their work, only the sensory neuron and not the postsynaptic target was most likely mutant as indicated by reflex behavior control of neighboring bristles (Burg and Wu, 1986, 1989).

A similar phenomenon, an increase in the extent of branching and the number of varicosities, was observed in a serotonin nerve projection to the digestive system of Drosophila larvae (Budnik et al., 1989a). This change was observed in larvae that were genetically deficient in serotonin and dopamine. It would be interesting to investigate if this change was also an activityrelated phenomenon generated by the lack of neurotransmitter action. Unfortunately, nothing is known about the electrophysiology of that enteric serotonin projection.

The effect of activity on the innervation of neuromuscular junctions has been studied in vertebrates. It has been found that motoneurons are saved from cell death by pre- or postsynaptic activity block that results in polyinnervation of the muscles (Laing and Prestige, 1978; Pittman and Oppenheim, 1979; Oppenheim, 1981). Conversely, electrical stimulation of the nerve results in enhanced neuronal cell death (Oppenheim and Nuñez, 1982). In Drosophila, the fact that intracellular recordings reveal 2 EJP sizes with different stimulation thresholds (Jan and Jan, 1976) suggests the presence of at least 2 motoncurons. Howcver, we found that the increase in branching observed in hyperex- citable mutants was in higher-order branches and not in the number of primary branches or branches emerging from the nerve (Fig. 7). This suggests that the increased size of the projection is probably not due to changes in the number of motoneurons innervating the muscles.

In adult vertebrate skeletal muscle, it has been found that blocking pre- or postsynaptic activity produces sprouting of motor endings (Brown and Ironton, 1977; Holland and Brown, 1980). We found that increasing rather than blocking activity seems to produce an increase in the size of muscle projections in Drosophila. Furthermore, the mutation nap, which decreases excitability, slightly reduces the branching of the projection. Similar to our studies, in crustacean neuromuscular junctions, an increase in the number of varicosities as a result of chronic stimulation has been reported (Lnenicka et al., 1986). One possibility to explain the observation in vertebrates is that, in those studies, activity was drastically blocked. In this and crustacean studies, only the activity level was modified.

\section{Possible mechanisms}

A question that remains to be answered is what aspect of neuronal activity could produce the morphological changes observed. Many studies have shown that synergistic interactions between $e a g$ and $S h$ or between $H k$ and eag increase the amount of neurotransmitter released many fold. In addition, it has been shown that these mutants show repetitive spontaneous action potentials (Ganetzky and Wu, 1983, 1985; Zhong and Wu, unpublished observations). In this report, the endogenous (presumably neurally evoked) activity was recorded extracellularly, and we were not able to measure parameters such as the amount of neurotransmitter released or the size of the postsynaptic potential. However, we were able to obtain information about the 
CNS-evoked temporal pattern of activity. We found that most wild-type muscle fibers displayed a rhythmic, bursting pattern of activity. In contrast, in most eag $S h$ and $H k$ eag muscle fibers, this bursting pattern was accompanied by a strong tonic (nonbursting) activity. Again, as with the morphological changes observed, nap ${ }^{s}$ also reversed the alterations in the pattern of activity in eag $S h$. However, in contrast to the morphological changes, this reversion was only partial. In eag $S h$ nap triple mutants, the predominant type of activity was similar to that of the wild type (bursting), but a low level of abnormal tonic activity was also present. These findings suggest that the level of activity (frequency of firing, size of the response, etc.) is not the only factor to be considered in activity-dependent changes, but that the temporal parameters need also to be taken into account.

Even though the implication is that hyperexcitability generates hyperinnervation, the mechanisms underlying this phenomenon are unknown. One possibility is that activity is necessary to stabilize newly generated synapses and neurites. In the presence of relatively low levels of activity, the probability that a given synapse would be stabilized is low, and therefore only a fraction of synapses are formed (Changeaux and Danchin, 1976). Another mechanism is that there are trophic interactions between nerve and muscle. For example, a trophic factor (which could be the neurotransmitter itself) whose release and/or transport is activity dependent could mediate both the increase in syraptic sites and the branching and growth of neurites. This suggestion seems to have some support in certain crayfish motoneurons. Lnenicka and Atwood (1989) applied an axonal conduction block to a small portion of a crayfish motor nerve and chronically stimulated the unblocked portion of the nerve, either proximal (near the neuronal cell body) or distal (near the neuromuscular synapse) to the block. They found that long-term physiological changes in the motoneuron nerve terminal activity (from phasic to tonic) could be produced only if the activity of the motoneuron cell body was altered. Changes of activity only in the axon and synaptic terminals did not produce any longterm change. In some vertebrate preparations, neuronal excitation is known to bring about gene expression in the nucleus via changes in the levels of second messengers (Morgan and Crrran, 1989).

In vertebrates, it has been proposed that synapses undergo continuous turnover. In neuromuscular junctions, presynaptic terminals unapposed to postsynaptic specializations (newly formed terminals), and postsynaptic specializations unapposed by presynaptic terminals (regressing synapses) are normally seen (Wernig et al., 1980; Anzil et al., 1984; Wernig and Fisher, 1986), though the molecular mechanisms that might regulate this dynamic process are still unknown. In the present study, we only looked at neuromuscular junctions of third-instar larvae. Therefore, we do not know the time course of the changes observed, for example, whether in the wild type there could be an early period of hyperinnervation followed by pruning, and whether this pruning is altered in hyperexcitable mutants. However, Johansen et al. (1989b) have looked at the embryonic development of the innervation of the body-wall muscles. At least up to first instar, they did not see any profuse ramification of neurites like the ones observed in this report. In this regard, it is interesting to note that we found an anteroposterior gradient in the degree of branching of nerve terminals. A parallel gradient in the levels of activity at certain developmental stages could explain these segmental differences. This hypothesis could be tested in our system by, for example, eliminating nerve activity in temperature-sensitive mutants for a relatively short period and examining the changes produced in the projections.

Bascd on our results, it can be suggested that the number of synaptic sites and the degree of branching of a given neuron could be the result of the degree of electrical activity of that neuron. Such a mechanism could provide the basis for both developmental and physiological plasticity. In Drosophila, a collection of mutations that affect different cellular growth and regulation mechanisms is available for further exploration of this activity-dependent phenomenon.

\section{References}

Anderson MS, Halpern ME, Keshishian H (1988) Identification of the neuropeptide transmitter proctolin in Drosophila larvae: characterization of fiber-specific neuromuscular endings. J Neurosci 8:242255.

Anzil AP, Bieser A, Wernig A (1984) Light and electron microscopic identification of nerve terminal sprouting and retraction in normal adult frog muscle. J Physiol (Lond) 350:393-399.

Atwood HL, Jahromi SS (1978) Fast-axon synapses in crab leg muscle. J Neurobiol 9:1-15.

Atwood HL, Johnston HS (1968) Neuromuscular synapses of a crab motor axon. J Exp Zool 167:457-470.

Bailey CH, Chen M (1988a) Long-term memory in Aplysia modulates the total number of varicosities of single identified sensory neurons. Proc Natl Acad Sci USA 85:2373-2377.

Bailey CH, Chen M (1988b) Long-term sensitization in Aplysia increases the number of presynaptic contacts onto the identified gill motor neuron L7. Proc Natl Acad Sci USA 85:9356-9359.

Baumann A, Krah-Jentgens I, Muller F, Muller-Holtkamp F, Siegel R, Kecskemethy N, Casal J, Ferrus J, Pongs O (1987) Molccular organization of the maternal effect region of the Shaker complex of Drosophila: characterization of an $I_{A}$ channel transcript with homology to vertebrate $\mathrm{Na}$ ' channel. EMBO J 6:3419-3429.

Brown MC, Ironton R (1977) Motoneurone sprouting induced by prlonged tetrodotoxin block of nerve action potential. Nature 265 : $459-461$.

Budnik V, Wu C-F, and White K (1989a) Altered branching of serotonin-containing neurons in Drosophila mutants unable to synthesize serotonin and dopamine. J Neurosci 9:2866-2877.

Budnik V, Zhong Y, Wu C-F (1989b) Projection of motor axons in hyperexcitable Drosophila mutants. Soc Neurosci Abstr 15:570.

Burg MG, Wu C-F (1986) Differentiation and central projections of peripheral sensory cells with action-potential block in Drosophila mosaics. J Neurosci 6:2968-2976.

Burg MG, Wu C-F (1989) Central projections of peripheral mechanosensory cells with increased excitability in Drosophila mosaics. Dev Biol 131:505-514.

Campos-Ortega JA, Hartenstein V (1985) The embryonic development of Drosophila melanogaster. New York: Springer.

Changeaux J-P, Danchin A (1976) Selective stabilization of developing synapses as a mechanism for the specification of neuronal networks. Nature 264:705-712.

Cohan CS, Kater SB (1986) Suppression of neurite elongation and growth cone motility by electrical activity. Science 232:1638-1640.

Crossley CA (1978) The morphology and development of the Drosophila muscular system. In: The genetics and biology of Drosophila, Vol 2b (Ashburner M, Wright TRF, eds), pp 449-559. New York: Academic.

Duchen LW, Strich SJ (1968) The effects of botulinum toxin on the pattern of innervation of skeletal muscle in the mouse. Q J Exp Physiol 53:84-89.

Englander LL, Rubin LL (1987) Acetylcholine receptor clustering and nuclear movement in muscle fibers in culture. J Cell Biol 104:87-95.

Ganetzky B (1984) Genetic studies of membrane excitability in Drosophila: lethal interaction between two temperature-sensitive paralytic mutations. Genetics 108:897-911.

Ganetzky B, Wu C-F (1982a) Drosophila mutants with opposing effects on nerve excitability: genetic and spatial interactions in repetitive firing. J Neurophysiol 47:501-514.

Ganetzky B, Wu C-F (1982b) Indirect suppression involving behav- 
ioral mutants with altered excitability in Drosophila melanogaster. Genetics 100:597-614.

Ganetzky B, Wu C-F (1983) Neurogenetic analysis of potassium currents in Drosophila: synergistic effects on neuromuscular transmission in double mutants. J Neurogenet 1:17-28.

Ganetzky B, Wu C-F (1985) Genes and membrane excitability in Drosophila. Trends Neurosci 8:322-326.

Ganetzky B, Wu C-F (1986) Neurogenetics of membrane excitability in Drosophila. Annu Rev Genet 20:13-44.

Gho M, Mallart A (1986) Two distinct calcium-activated currents in larval muscle fibers of Drosophila melanogaster. Pflugers Arch 407: 526-533.

Gorczyca M, Wu C-F (1991) Single-channcl K+ currents in Drosophila muscle and their pharmacological block. J Membrane Biol (In press).

Halpern ME, Anderson MS, Johansen J, Keshishian H (1988) Octopamine immunoreactive nerve terminals are found on a single identified muscle fiber of the Drosophila larval body wall. Soc Neurosci Abstr 14:383.

Harris WA (1980) The effects of eliminating impulse activity on the development of the retinotectal projection in salamander. J Comp Neurol 194:303-317.

Harris WA (1981) Neural activity and development. Annu Rev Physiol 43:689-710.

Haugland F, Wu C-F (1990) A voltage-clamp analysis of gene dosage effects of the Shaker locus on larval muscle potassium currents in Drosophila. J Neurosci 10:1357-1371.

Hill RH, Govind CK (1981) Comparison of fast and slow synaptic terminals in lobster muscle. Cell Tissue Res 221:303-310.

Holland RL, Brown MC (1980) Postsynaptic transmission block can cause terminal sprouting of a motor nerve. Science 207:649-651.

Hubel DH, Wiesel TN, LeVay S (1977) Plasticity of ocular dominance columns in monkey striate cortex. Philos Trans R Soc Lond [Biol] 278:377-409.

Ikeda K, Kaplan WD (1970) Patterned neural activity of a mutant of Drosophila melanogaster. Proc Natl Acad Sci USA 66:765-772.

Jackson FR, Wilson SD, Strichartz GR, Hall LM (1984) Two types of mutants affecting voltage-sensitive sodium channels in Drosophila melanogaster. Nature 308:189-191.

Jan LY, Jan YN (1976) L-Glutamate as an excitatory transmitter at the Drosophila larval neuromuscular junction. J Physiol (Lond) 262: 215-236.

Jan LY, Jan YN (1982) Antibodies to horseradish peroxidase as specific neuronal markers in Drosophila and grasshopper embryos. Proc Natl Acad Sci USA 72:2700-2704.

Jan YN, Jan LY, Dennis MJ (1977) Two mutations of synaptic transmission in Drosophila. Proc R Soc Lond [Biol] 198:87-108.

Johansen J, Halpern ME, Johansen KM, Keshishian H (1989a) Stereotypic morphology of glutamatergic synapses on identified muscle cells of Drosophila larvae. J Neurosci 9:710-725.

Johansen J, Halpern ME, Keshishian H (1989b) Axonal guidance and the development of muscle fiber specific innervation in Drosophila embryos. J Neurosci 9:4318-4332.

Kamb A, Iverson LE, Tanouye MA (1987) Molecular characterization of Shaker, a Drosophila gene that encodes a potassium channel. Cell 50:405-413.

Kandel ER, Klein M, Castellucci VF, Schacher S, Goelet P (1986) Some principles emerging from the study of short- and long-term memory. Neurosci Res 3:498-520.

Kaplan WD, Trout WE (1969) The behavior of four neurological mutants of Drosophila. Genetics 61:399-409.

Kauvar LM (1982) Reduced [ $\left.{ }^{3} \mathrm{H}\right]$-tetrodotoxin binding in the nap ${ }^{\prime s}$ paralytic mutant of Drosophila. Mol Gen Genet 187:172-173.

Kelly AM, Zacks SI (1969) The fine structure of motor endplate morphogenesis. J Cell Biol 42:154-169.

Kernan M, Kuroda M, Baker BS, Ganetzky B (1989) nap ${ }^{r s}$ and mle: mutations in one gene affecting sodium channel activity and transcriptional control in Drosophila. Soc Neurosci Abstr 15:196.

Komatsu A, Singh S, Rathe P, Wu C-F (1990) Genetic manipulation of calcium-activated potassium channels: correlation of microscopic and macroscopic currents. Neuron 4:313-321.

Laing NH, Prestige MC (1978) Prevention of spontaneous motoneurone death in chick embryos. J Physiol (Lond) 282:33-34P.

Lindsley DL, Grell EH (1968) Genetic variations of Drosophila melanogaster. Carnegie Institution of Washington, Publication No. 627.

Lnenicka GA, Atwood HL (1989) Impulse activity of a crayfish mo- torneuron regulates its neuromuscular synaptic properties. J Neurophysiol 61:91-96.

Lnenicka GA, Murphey RK (1989) The refinement of invertebrate synapses during development. J Neurobiol 20:339-355.

Lnenicka GA, Atwood HL, Marin L (1986) Morphological transformation of synaptic terminals of a phasic motoneuron by long-term tonic stimulation. J Neurosci 6:2252-2258.

Loer CM, Kristan WB Jr (1989) Central synaptic inputs to identified leech neurons determined by peripheral targets. Science 244:64-66.

Loer CM, Jellies J, Kristan WB Jr (1987) Segment-specific morphogenesis of leech Retzius neurons requires particular peripheral targets. J Neurosci 7:2630-2638.

Loughncy K, Kreber R, Ganetzky B (1989) Molecular analysis of the para locus, a sodium channel gene in Drosophila. Cell 58:1143-1154.

Meinertzhagen IA (1989) Fly photoreceptor synapses: their development, evolution, and plasticity. J Neurobiol 20:276-294.

Meyer RL (1982) Tetrodotoxin blocks the formation of ocular dominance columns in goldfish. Science 218:589-591.

Morgan JI, Curran T (1989) Stimulus-transcription coupling in neurons: role of cellular immediate-early genes. Trends Neurosci 12:459462.

Murphey RK (1986) The myth of the inflexible invertebrate: competition and synaptic remodelling in the development of invertebrate nervous systems. J Neurobiol 17:585-591.

Murphey RK, Lemere CP (1984) Competition controls the growth of an identified axonal arborization. Science 224:1352-1355.

Nakai J (1968) The development of neuromuscular junctions in cultures of chick embryo tissues. J Exp Zool 170:85-106.

Oppenheim RW (1981) Cell death of motoneurons in the chick embryo spinal cord. V. Evidence on the role of cell death and neuromuscular function in the formation of specific peripheral connections. J Neurosci 1:141-151.

Oppenheim RW, Nuñez R (1982) Electrical stimulation of hindlimb increase neuronal cell death in chick embryo. Nature 285:57-59.

Osborne MP (1975) The ultrastructure of nerve-muscle synapses. In: Insect muscle (Usherwood PNR, ed), pp 151-205. New York: Academic.

Papazian DM, Schwartz TL, Tempel BL, Jan YN, Jan LY (1987) Cloning of genomic and complementary DNA from Shaker, a putative potassium channel gene from Drosophila. Science 237:749753.

Pittman R, Oppenheim RW (1979) Cell death of motoneurons in the chick embryo spinal cord. IV. Evidence that a functional neuromuscular interaction is involved in the regulation of naturally occurring cell death and the stabilization of synapses. J Comp Neurol 187:425446.

Salkoff L, Wyman R (1981) Genetic modification of potassium channels in Drosophila Shaker mutants. Nature 293:228-230.

Sanes DH, Constantine-Paton M (1983) Altered activity patterns during development reduce neural tuning. Science 221:1183-1185.

Schmidt JT, Edwards DL (1983) Activity sharpens the map during the regeneration of the retinotectal projection in goldfish. Brain Res 269:29-39.

Schmidt JT, Tieman SB (1989) Activity, growth cones and the selectivity of visual connections. Comments Dev Neurobiol 1:11-28.

Shepherd D, Murphey RK (1986) Competition regulates the efficacy of an identified synapse in crickets. J Neurosci 6:3152-3160.

Siddiqi O, Benzer S (1976) Neurophysiological defects in temperaturesensitive paralytic mutants of Drosophila melanogaster. Proc Natl Acad Sci USA 73:3253-3257.

Singh S, Wu C-F (1989) Complete separation of four potassium currents in Drosophila. Neuron 2:1325-1329.

Stern M, Ganetzky B (1989) Altered synaptic transmission in Drosophila Hyperkinetic mutants. Neurogenet 5:215-228.

Stern M, Kreber R, Ganetzky B (1990) Dosage cffcets of a Drosophila sodium channel gene on behavior and axonal excitability. Genetics 124:133-143.

Suzuki DT, Grigliatti T, Williamson R (1971) Temperature-sensitive mutants in Drosophila melanogaster VII. A mutation (para ${ }^{\text {ts }}$ ) causing reversible adult paralysis. Proc Natl Acad Sci USA 68:890-893.

Technau GM (1984) Fiber number in the mushroom bodies of adult Drosophila melanogaster depends upon age, sex, and experience. J Neurogenet 1:113-126.

Tempel BL, Papazian DM, Schwartz TL, Jan YN, Jan LY (1987) 
Sequence of a probable potassium channel component encoded at the Shaker locus of Drosophila. Science 237:770-775.

Timpe LC, Jan LY (1987) Gene dosage and complementation analysis of the Shaker locus in Drosophila. J Neurosci 7:1303-1317.

Titmus MJ (1981) Ultrastructure of identified fast excitatory, slow excitatory, and inhibitory neuromuscular junctions in the locust. $\mathrm{J}$ Neurocytol 10:363-385.

Wernig A, Fisher M (1986) The nerve-muscle junction: a remodeling contact. Exp Brain Res 14:245-255.

Wernig A, Pécot-Dechavassine M, Stöver H (1980) Sprouting and regression of nerve at the frog neuromuscular junction in normal conditions and after prolonged paralysis with curare. J Neurocytol 9: 277-303.

Wu C-F, Ganetzky B (1980) Genetic alteration of nerve membrane excitability in temperature-sensitive paralytic mutants of Drosophila melanogaster. Nature 286:814-816.

Wu C-F, Ganetzky B (1988) Genetic and pharmacological analyses of potassium channels in Drosophila. In: Molecular basis of drug and pesticide action, Ch 23 (Lunt GG, ed), pp 311-323. New York: Elsevier.

Wu C-F, Haugland FN (1985) Voltage clamp analysis of membrane currents in larval muscle fibers of Drosophila: alterations of potassium currents in Shaker mutants. J Neurosci 5:2626-2640.

Wu C-F, Ganetzky B, Jan LY, Jan YN, Benzer S (1978) A Drosophila mutant with a temperature-sensitive block in nerve conduction. Proc Natl Acad Sci USA 75:4047-4051.

Wu C-F, Ganetzky B, Haugland FN, Liu AX (1983) Potassium currents in Drosophila: different components affected by mutations of two genes. Science 220:1076-1078.

Yamaoka K, Ikeda K (1988) Electrogenic responses elicited by transmembrane depolarizing current in aerated body wall muscles of Drosophila melanogaster. J Comp Physiol 163:705-714.

Zagotta WN, Brainard MS, Aldrich RW (1988) Single-channel analysis of four distinct classes of potassium channels in Drosophila muscle. J Neurosci 8:4765-4779. 